\title{
Chaotic Assessment of the Heave and Pitch Dynamics Motions of Air Cushion Vehicles
}

\author{
Ahmed Sowayan, Imam Mohammad Ibn Saud Islamic University, Saudi Arabia \\ iD https://orcid.org/0000-0003-3843-929X
}

\begin{abstract}
In this study, three degrees of freedom nonlinear air cushion vehicle (ACV) model is introduced to examine the dynamic behavior of the heave and pitch responses in addition to the cushion pressure of the ACV in both time and frequency domains. The model is based on the compressible flow Bernoulli's equation and the thermodynamics nonlinear isentropic relations along with the Newton's second law of translation and rotation. In this study, the dynamical investigation was based on numerical simulation using the stiff ODE solvers of the Matlab software. The chaotic investigations of the proposed model are provided using the fast Fourier transform (FFT), the Poincare maps, and the regression analysis. Three control design parameters are investigated for the chaotic studies. These parameters are ACV mass (M), the mass flowrate entering the cushion volume ( $\mathrm{m}$ _in), and the ACV base radius (r). Chaos behavior was observed for heave and pitch responses as well as the cushion pressure.
\end{abstract}

\section{KEYWORDS}

Air Cushion Vehicles, Bernoulli's Equation, Chaos, Fast Fourier Transform (FFT), Heave Motion, Pitching Motion, Poincaré Map

\section{INTRODUCTION}

Air Cushion Vehicles (ACV) are mainly operated by highly pressurized air which is fed to the air cushion using blowers. The flow of air is maintained due to a momentum change at the high-velocity peripheral air curtain. These blowers yield a large volume of air cushion that has a pressure, a little higher than the atmospheric pressure creating a pressure difference. This pressure difference produces vehicle lift, which causes the bottom air cushion to float above the running surface. The ACVs have the capability to function in many different environments that can be coarse such as ice, water, or forests.

The hydrodynamic action of the ACV is ideally equivalent to that of a pressure distribution acting on the free surface of water. This idealization prohibits any physical contact of the lower part of the ACV with the water (Bliault, A., 2000). Abundant studies were performed in the literature regarding proper designing and dynamics of these vehicles. The rest of this section is a summary of the related study that are available in the literature.

A linear analysis of a two-dimensional section of the cushion equipped with a bag-and-finger skirt was subjected to only input heave motion by Chung et al. (2000). The skirt mass was lumped in the fingers, with the bag being modeled as a combination of massless inelastic membranes and links. The findings of the study suggested that changes in skirt geometry could not be used to radically modify an undesirable heave response, but reducing the skirt mass might be effective. They also found in 
their study that the air compressibility affected the heave response at high frequencies, with the effect becoming more prominent at low cushion-flow rates commonly used in practice.

All prior research studies combined together formed the basis of a standard physics-based dynamic simulation model for ACVs. It should be noted that the response motions computed from the previous physical simulation models of the ACVs did not display similar response when compared with the experimental results of the scaled-model tests. Lack of understanding the physical damping mechanisms in the ACV motion led to the discrepancy between the simulations and experiments. Wave generation on the free surface and deformation of the viscoelastic skirt material was used as a damping source by Chung (2002) in his investigation while Graham and Sullivan (2002) researched the effect of other sources of damping on the motion of the ACVs, such as the unsteady air flow throughout the fan, skirt, and cushion system.

The general configuration of ACVs including the overall dimensions, weight distribution, parametric properties, and several subsystems, was designed and optimized by Jung et al. (2002) using the expert system at the initial design phase. The skirt bag and finger systems of ACV were further optimized for improving ride quality and stability of the vehicle using the genetic algorithm. Hence, Chung's work opened up the new avenues for designing ACVs using artificial intelligence techniques. Chung et al. (2004) also used the Genetic Algorithm to optimize the undesirable two dimensional section heave response of the ACV's bag and finger skirt system geometry. They obtained a new skirt geometry that considerably improved the resonating frequencies associated with the skirt mass at which humans were most sensitive.

An analytical model of was introduced by Pollack et al. (2007) to investigate the dynamics of an ideal air cushion cavity of an ACV. The study revealed that skirt impedance strongly affected the resonant frequencies and mode shapes of the ACV. The impedance of modern skirt systems could also dramatically alter the air cushion enclosed volume and vehicle footprint, thus influencing the system resonances and restoring moments Pollack et al. (2007).

Compressibility effect on the dynamic behavior of an ACV was investigated by Milewski et al. (2007) and Milewski et al. (2008) utilizing the deformable free surface condition. The governing equations introduced by Milewski et al. (2007) were solved on a fixed regular grid translating at the vehicle mean forward speed using the Immersed Boundary Method (IBM). Whereas, Milewski et al. (2008) developed a numerical program called ACVSIM (Air Cushion Vehicle Simulation), that used the boundary element method with a higher order spline based model to study the skirt and the ACV dynamics. ACVSIM coupled a high-order Rankine panel method with models for air cushion and skirt dynamics to calculate the motions of the ACV.

The incompressible viscous nuid mechanics problem around ACV near the free surface was investigated numerically using the Semi-Implicit Method for Pressure Linked Equations (SIMPLE) algorithm and volume of fluid (VOF) method with staggered grid by Nikseresht et al. (2008). Many parameters were examined in the numerical procedure such as the ACV under skirt pressure distribution, initial air gap under the ACV, and effect of Froude number. A versatile and robust computational coding was done and tested in their study by applying the code on a water impacted cylindrical part of the ACV.

Hossain, et al. (2011) presented a new dynamical model for the forces on a small scale intelligent air cushion tracked vehicle (IACTV) moving over swamp peat. The air cushion system in their study partially supported $25 \%$ of vehicle's total weight making the vehicle ground contact pressure $7 \mathrm{kN} / \mathrm{m},{ }^{2}$ in order to make the IACTV move over the intended terrain without threats. They also mentioned that the relationships between the various vehicle parameters had been experimentally tested. Some of these parameters were: tractive efficiency, power consumption, traction coefficient, load distribution ratio, tractive effort etc. Experimental and simulated results showed a considerable improvement in the vehicle's performance when values of 0.71 and 0.62 were used for the traction coefficient and tractive efficiency respectively. 
Xie et al. (2013) designed an air cushion system using computational fluid dynamics (CFD) simulation in which the relationships among some of the design parameters of the ACV were obtained from measurement. These parameters included vehicle's fan rotational speed, equivalent clearance height, and static air cushion pressure convert ratio. The results of their study provided good benchmarks for the design of vehicles with air-cushion system. Ji (2012) developed a comprehensive mathematical model for a 6-DOF motion control for ACVs. He obtained his model by superimposing the wave-making water surface deformation in calm water and wave waveforms in external environment. The results of this study produced in an optimized maneuverability-control system of ACVs.

The 6-DOF motion model of an ACV based on Newton's momentum and moment of momentum theorem was developed by Zhang et al. (2012). In their study, they obtained the water surface deformation under the air cushion by applying linear wave theory, the lift fan, air duct, skirt, and air cushion dynamic balancing were achieved by balancing flow across each which resulted in a stable motion of the vehicle. Earlier Sowayan et al. (2012) used the compressible Bernoulli's equation and the Newton's second law of translation motion to predict the vanishing oscillatory motion of an ACV. In that study, only the ACV's heave degree of freedom was considered, which was shown to have a periodic behavior.

Han et al. (2017) assessed the trajectory tracking of ACVs using a new multivariable higherorder sliding mode (HOSM) control scheme that allowed the ACVs to be modeled as an uncertain nonlinear system with lesser degrees of freedom. The ACV was modeled by a nonlinear dynamic model that was externally disturbed by certain environmental characteristics. The control approach included stabilized nominal continuous control law and super-twisting second-order sliding mode control part to reduce chattering of controlling force in surge and yaw motion. Lyapunov exponent approach was used to judge the motion finite time stability in terms of robustness and superiority Han et al. (2017).

A mathematical model of an ACV with a ballonet type skirt was developed and solved using numerical integration by Eremeyev et al. (2017). Many parts of the ACV such as the rigid body, air cushion, propulsion system, ballonet, fundamental surface etc. were dynamically incorporated in the model. The proposed model was subjected to different operating conditions and was found to be capable of accurately predicting all major characteristics of the ACV motion such as trajectory, forces, moments, air cushion pressure etc. when subjected to different operating conditions. The featured motion calculated using the model was found to be in good agreement with the results of the model towing tests in calm water and in waves. The model was also capable of designing the preliminary design stages of the ACV's body structure to simulate the both controlled and uncontrolled dynamics of ACV's spatial movement on still and wavy water surface.

Wang et al. (2017) designed a second order nonsingular terminal sliding mode controller with extended state observer of an ACV using extended state observer and second order nonsingular terminal sliding mode heading controller to improve the safety and maneuverability of ACVs. One of the physical causes that reduce the maneuverability of ACV is the chattering, which can be eliminated by introducing an extended state observer to evaluate the nonlinear uncertainties and external disturbances in the ACV. Lyapunov analysis was performed to analyze the stability of closed loop system of the considered ACV.

The dynamic modelling and parameter estimation of Unmanned Air Cushion Vehicle (UACV) was investigated by Ab Rashid et al (2017). They studied a dynamic model of the vehicle with six degrees of freedom using the Euler-Lagrange method. The six degrees of freedom consisted of the heave, sway, surge, roll, pitch and yaw motions. Solidworks ${ }^{\circledR}$ software was used to obtain and calculate the parameters of the system. The parameters that were investigated included body inertia of the system and air mass flow rate flowing into the UACV skirt. The results of the study were validated from other published experimental and simulation studies. 
Fu et al. (2019) studied a hovercraft model having four degrees of freedom with unknown curve-fitted coefficients using constrained adaptive Lyapunov function controller in yaw path that was varying with the speed of the hovercraft. The desired virtual yaw rate was generated using the command filter with a time-varying magnitude limit that led to a reduction in the computational complexity. Theoretical analyses indicated that the position tracking error constraint and the yaw rate constraint could be strictly guaranteed by using the proposed controller. It was also shown that, since hovercrafts normally have high surge velocities, the time variation delay could result in the measurements.

A numerical dynamic explicit finite element parametric-driven based method has been used to optimize the skirt configuration of ACVs. Some geometrical parameters were considered in this study such as length ratio between the inner and outer bag, anti-bounce web size. It was shown by Xu et al. (2019) that the configuration of bow-side corner skirt optimized by the parametric-driven finite element method had a uniform skirt height distribution which is beneficial to the overall performance of air cushion vehicle. The pressure responsiveness properties of a skirt-cushion system have been investigated by Xu et al. (2020) numerically using cushion aerodynamics and flexible skirt dynamics. A cushion-skirt information communication platform has been also presented for interchanging the force and the skirt configuration between cushion aerodynamics and flexible skirt dynamics. The results demonstrate that the pressure responsiveness property helps alleviate the influence of the cushion height changing on the overall performance of ACVs (Xu et al., 2020).

Many studies in the literature tackled chaotic dynamical systems analysis using the Lyapunov Exponent Spectrum, bifurcation diagram, phase portrait, time series, Poincaré maps. Poincare surface of section has been used by Trikha et al. (2020) to identify the dynamical analysis of a new 4-D hyperchaotic system for secure communication. The chaos investigation used in this study was enriched by the various control techniques such as active, adaptive, and tracking control of Balochian et al. (2018).

This paper is divided into six sections including this introduction. Introduction section is followed by a section on Problem Statement and Motivations, which exactly describes the research problem being studied and the objectives and motivation behind this study. The next section on the Methodology and Governing Equations, which exactly describes the comprehensive derivations of the mathematical model and its method of solution. The forth section discusses the method of solution of the current model and presents some results of this study in details. The fifth section describes complete study of the Chaos Investigation, while the last section draws the conclusions.

\section{PROBLEM STATEMENT AND MOTIVATIONS}

In this study, the dynamic behavior for an air cushion vehicle ACV model is introduced using the basics of thermodynamics and fluid mechanics. The proposed model has two degrees of freedom, which are (i) the vertical motion (heave) and (ii) the pitching motion (rotation). The air cushion pressure is also included in the investigation. The model is nonlinear, and the nonlinearity is due to many reasons, which will be explained a later section of this paper. The sources of nonlinearity lead to self-excitation of the model, which is affected by several design parameters but only three of these parameters have been selected for the chaotic investigation. These are (i) mass of the vehicle $(M)$, (ii) the ACV skirt perimeter which is related to ACV base radius ( $r$ ), and (iii) the air mass flow rate into the cushion volume ( $\left.\dot{m}_{\text {in }}\right)$.

The novelties of this study involves the evaluation of the following dependent variables (heave, vertical velocity, cushion pressure, angular rotation motion, and angular velocity in the pitching direction). Also the chaotic and fractal dynamics are also investigated for all dependent variables, which is up to the author knowledge has not been investigated before.

Most ACV models including the model considered in this study are self-excited models, and therefore unwanted oscillatory motions exist in their start operations. The oscillatory motions are 
translation in the vertical and azimuthal directions at the transient response of the solution. These motions are undesirable as sometimes they may lead to chaos behavior of the ACV motion. Therefore, another objective of this study is to explore the impact of the chosen design parameters on the chaotic transient response in order to assess the oscillatory behavior of ACV.

\section{METHODOLOGY AND GOVERNING EQUATIONS}

The model presented in this paper is based on many physical and mathematical assumptions. There are some specific assumptions will be stated during the derivation of the mathematical model of the problem. The other assumptions are presented in this section as follows:

1. The working fluid in this study is pressurized air inside the cushion volume underneath the ACV.

2. The flow of air from the cushion as shown in Figure (1) is assumed to be subsonic and compressed isentropically.

3. Also, thermodynamic equilibrium is assumed inside the cushion volume. Furthermore, the ACV geometry is assumed to be symmetrical about the heave motion axis.

4. Lumped capacitance of the cushion volume and the extended skirt are assumed which allows clearance surface contact that enables air flow to escape through a uniform hovergap as displayed in Figure (1).

5. Motion of the ACV is only in the heave and pitch directions.

6. Only three design parameters as mensioned in the previous section were chosen for studyning the dynamics behavior of the model in this paper.

7. To be not branched out, the following model's parameters were fixed. Thses parameters are as follows: skirt length $(L)$, metacenter distance $(h)$, ACV height from ground $(d)$, air temperature $(T)$, and the correction coefficient factor $\left(c_{0}\right)$.

ACVs have been found to experience a fierce oscillatory heave motion that is coupled with pitch motion. This is due to the interaction of its mechanical motion and the air behavior of the cushion volume. Therefore, the governing equation needs to be coupled to correctly predict this interaction. Moreover, the mathematical model that is going to be introduced in this study will enable one to understand the nature of ACV's response. It will help ACV designers to redesign the ACV's system response in a way that can eliminate violent oscillatory motion. The equations of motion for the ACV's heave and pitching motion are derived in the next subsections.

\subsection{Heave Motion Governing Equations}

Using Newton's Second law of motion, the balance forces on the vehicle in the $z$-direction leads to the vertical equation of motion as:

$$
M z=\left(p-p_{a}\right) A-M g-F_{\mathrm{M}}
$$

where $M$ is the mass of the vehicle, $z$ is the acceleration in the vertical direction, $p$ is the inside cushion pressure, $p_{a}$ is the atmospheric pressure, $g$ is the gravitational acceleration, $A$ is the ACV base cross-sectional area of the cushion, which is assumed to be of a circular having a radius $r$, and $F_{\mathrm{M}}$ is the change in momentum force due to the flow of the air mass. $F_{\mathrm{M}}$ represent some kind of thrust force which moves the ACV up through in the air. This force is produced by the air mass flowrate originated from the blowers which are connected to the ACV engine. It is basically generated through the reaction of accelerating the mass of the air in and out of the ACV. 
Figure 1. Air mass flow rate leaving the cushion volume, and pressure distribution across the footprint of ACV.

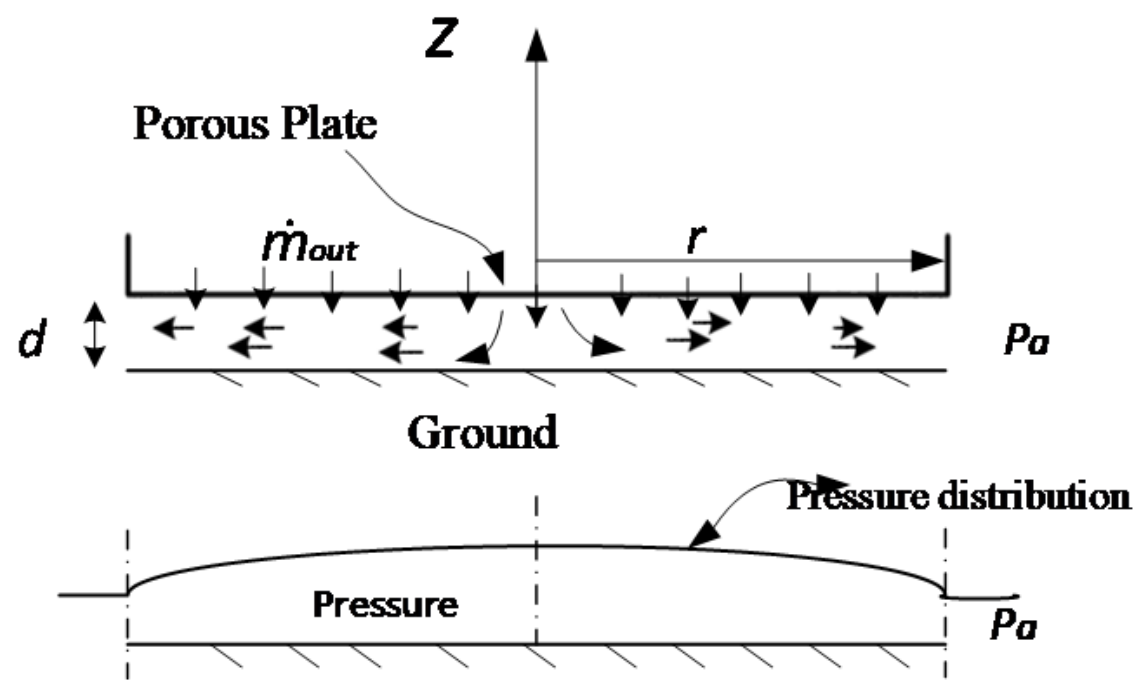

\section{Ground}

Figure 2. Air Cushion Vehicle movements - (Part A) motion in the heave direction, (Part B) pitch motion with the forces causing rotation of the ACV body, (Part C) the ACV base cross-sectional area with pressure force acting at the geometric center, (Part $D)$ seal form of the air leakage under ACV.

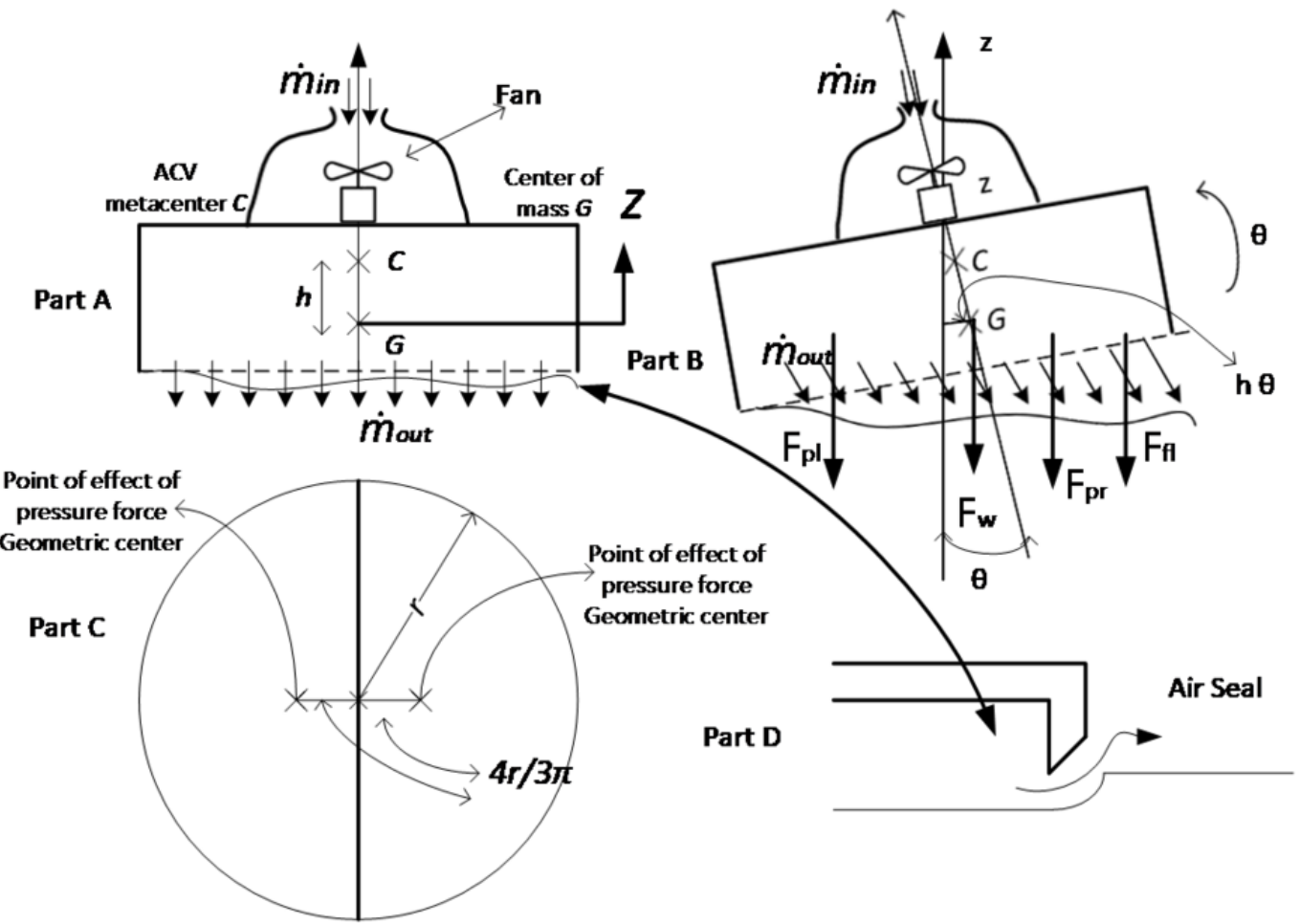


It should be noted that cushion pressure is assumed homogenous throughout the base of the ACV as shown in Figure (1) (Bliault 2000). The change of cushion pressure with time is derived in a previous work (Sowayan et al. (2013)) of the author to be:

$$
\dot{p}=\frac{\gamma R T}{V}\left[\dot{m}_{\text {in }}-\dot{m}_{\text {out }}-\frac{p A \dot{z}}{R T}\right]
$$

Where $\gamma$ is the specific heats ratio, $R$ is the air gas constant, $T$ the air flowing temperature out of the cushion volume, and $\dot{m}_{\text {in }}$ is a fixed mass flow rate entering the cushion volume. The mass flowrate $\dot{m}_{\text {in }}$ to the cushion volume depends on the fan power that is attached to the ACV's engine. It is assumed to be a fixed value due to its dependency of the kinetic energy of the air which is generated by the blower fan power. One can use the first law of thermodynamics to show that the $\dot{m}_{\text {in }}=\dot{W} / k e$, where $\dot{W}$ is the fan power, and ke is the kinetic energy of the air before and after the fan. This is an acceptable approximation since the flow is assumed to be isothermal flow.

The cushion volume $V$ is defined as $V=A \times(z+d)$, where $z$ is the vertical distance of the vehicle, and $d$ is the ACV vertical distance from the ground. The mass flow rate exiting the cushion $\dot{m}_{\text {out }}$ is derived by applying the compressible Bernoulli's equation, and is given by Sowayan et al. (2013) as:

$$
\dot{m}_{\text {out }}=\frac{c_{0} p L z}{\sqrt{R T}}\left\{\frac{2 \gamma}{\gamma-1}\left[\left(\frac{p_{a}}{p}\right)^{\frac{2}{\gamma}}-\left(\frac{p_{a}}{p}\right)^{\frac{(\gamma+1)}{\gamma}}\right]\right\}^{\frac{1}{2}}
$$

The momentum force associated with air mass flow is evaluated as follows:

$$
F_{\mathrm{M}}=\dot{m} \times \text { Vehicle Velocity }
$$

where $\dot{m}$ is the air mass flowrate and is given to be $\left(\dot{m}_{\text {in }}-\dot{m}_{\text {out }}\right)$. The vehicle velocity has two components: one component is in the heave direction $(z)$ and the other component is in the pitch coordinate $(\theta)$ which is equal to $r \dot{\theta}$. The vehicle velocity is calculated for the two components using the cosine law as flows:

Vehicle Velocity $=\sqrt{(\dot{z})^{2}+(r \dot{\theta})^{2}-2 r z \dot{\theta} \cos \theta}$

where $r$ is the radius of the ACV base, $\theta$ is pitch angular displacement, and $\dot{\theta}$ is the angular velocity of the ACV. Equation (5) can be simplified using the fact that the pitch angular displacement $\theta$ is small (Nayfeh 2011), therefore, $\cos \theta \approx 1$, which yields the vehicle velocity to be:

Vehicle Velocity $=\sqrt{(\dot{z})^{2}+(r \dot{\theta})^{2}-2 r \dot{z} \dot{\theta}}=(\dot{z}-r \dot{\theta})$ 
Therefore, by using Equation (4) the force due to momentum flow can be written as:

$$
F_{\mathrm{M}}=\left(\dot{m}_{\mathrm{in}}-\dot{m}_{\text {out }}\right) \times(\dot{z}-r \dot{\theta})
$$

It should be noted that $\dot{m}_{\text {out }}$ is evaluated using Equation (3). Lastly, Equation (7) is substituted into Equation (1), which yields the equation for the vertical motion of the vehicle given as:

$$
M z=\left(p-p_{\text {a }}\right) A-M g-\left(\dot{m}_{\text {in }}-\dot{m}_{\text {out }}\right) \times(\dot{z}-r \dot{\theta})
$$

\subsection{Pitch Motion Governing Equations}

The cushion geometry of the ACV is the most relevant factor for pitch restoring motion. The ACV is considered to be operating in the cases of fixed surface and free surface together as shown in Figure (2). When the ACV is in heave motion only, the metacenter $C$ of the ACV due to the cushion pressure is aligned with the center of mass $G$, an equilibrium state will be created. When the vehicle is disturbed with pitch motion by an angle $\theta$, the center of mass $G$ moves to the right through a distance $(h \theta)$. This indicates a positive moment for $G$ because the center of mass $G$ cannot be negative for an air cushion vehicle.

For an ACV with two symmetric chambers divided into left and right parts the force caused by the cushion pressure is distributed to the two parts; the right pressure force $F_{\mathrm{pr}}$ which will decrease the cushion pressure by an amount $\left(p-p_{\mathrm{a}}\right) \theta$. Conversely, the left pressure force $F_{\mathrm{pl}}$ will increase the cushion pressure by an amount $\left(p-p_{a}\right) \theta$. Eventually the oscillation occurs in the $\theta$-direction due to the physical tendency of the vehicle to return to equilibrium. The point of action of these two forces is at the geometric center of the ACV base, which is located at the half circle on both sides of the ACV base. This is depicted in Figure (2) part $C$. Consequently, the moment arm of the pressure forces is $\frac{4}{\pi} r$ where $\mathrm{r}$ is the radius of the ACV base. Therefore, the cushion pressure moment for the right pressure force $F_{\mathrm{pr}}$ and left pressure force $F_{\mathrm{pl}}$ is evaluated as:

$$
\mathcal{M}_{p}=\left(p-p_{a}\right) \times(1+\theta) \times \frac{4}{3 \pi} r \times \frac{A}{2}-\left(p-p_{a}\right) \times(1-\theta) \times \frac{4}{3 \pi} r \times \frac{A}{2}
$$

where $A$ is base cross-sectional area of the ACV and it is equal to $\pi r^{2}$. One can simplify this equation as:

$$
\mathcal{M}_{\mathrm{p}}=\frac{4}{3} r^{3}\left(p-p_{\mathrm{a}}\right) \theta
$$

The weight force $(M g)$ has a moment arm of $(h \theta)$, and the force associated with air momentum mass flowrate $\left(F_{M}\right)$ has a moment arm $r \cos \theta$. However, for small pitch angle $\theta$ the moment arm of $F_{\mathrm{M}}$ is simply equal to $r$. To express the motion of the ACV in the pitch direction, one can use Newton's second law of rotation $\left(\sum \mathcal{M}_{\mathrm{G}}=I \theta\right)$ as follows: 


$$
I \ddot{\theta}=\frac{4}{3} r^{3}\left(p-p_{\text {a }}\right) \theta-M g(h \theta)-\left(\dot{m}_{\text {in }}-\dot{m}_{\text {out }}\right) \times(\dot{z}-r \dot{\theta}) \times r
$$

Or

$$
I \theta=\frac{4}{3} r^{3}\left(p-p_{\mathrm{a}}\right) \theta-M g(h \theta)-\left(\dot{m}_{\text {in }}-\frac{c_{0} p L z}{\sqrt{R T}}\left\{\frac{2 \gamma}{\gamma-1}\left[\left(\frac{p_{\mathrm{a}}}{p}\right)^{\frac{2}{\gamma}}-\left(\frac{p_{\mathrm{a}}}{p}\right)^{\frac{(\gamma+1)}{\gamma}}\right]\right]^{\frac{1}{2}}\right] \times(\dot{z}-r \dot{\theta}) \times r
$$

where $I$ is the ACV moment of inertia about its center of mass. Equations (1), (2), (3), (8), and (12) are solved numerically in the following section.

\section{RESULTS AND DISCUSSION}

The governing nonlinear stiff system of ordinary differential equations (1), (2), (3), (8), and (12) are solved numerically using the implicit Runge-Kutta numerical integration method. This can be performed by converting the system of governing equations into a system of first order ordinary differential equation by state space analysis equations (13) to (17). This solution method is adopted in this study because it has the necessary numerical stability that is essential to solve the current system of differential equations.

$$
z_{1}=z_{2}
$$

$\theta_{1}=\theta_{2}$

$$
z_{2}=\frac{A}{M}\left(p-p_{\mathrm{a}}\right)-g-\frac{1}{M}\left(\dot{m}_{\text {in }}-\dot{m}_{\text {out }}\right) \times\left(z_{2}-r \theta_{2}\right)
$$

$$
\dot{\theta}_{2}=\frac{1}{I}\left\{\frac{4}{3} r^{3}\left(p-p_{\mathrm{a}}\right) \theta_{1}-M g\left(h \theta_{1}\right)-\left(\dot{m}_{\text {in }}-\dot{m}_{\text {out }}\right) \times\left(z_{2}-r \theta_{2}\right) \times r\right\}
$$

and

$$
\dot{p}=\frac{\gamma R T}{A\left(d+z_{1}\right)}\left[\dot{m}_{\text {in }}-\dot{m}_{\text {out }}-\frac{p A z_{2}}{R T}\right]
$$


To solve this system of first order ordinary nonlinear differential equations numerically, a Matlab M-file program is written that uses a fixed time step Runge-Kutta method. The accuracy of the results depends on the type of solver used in the Matlab. During the numerical simulation, it was noticed in the governing equations that a small change in some of the terms can lead to quick and big changes in the solution. Therefore, this system is considered a stiff system. The Matlab simulation uses the following initial conditions:

$$
\begin{aligned}
& z(t=0)=0.001 \mathrm{~m}, \dot{z}(t=0)=0.001 \mathrm{~m} / \mathrm{s} \\
& p(t=0)=101000 \mathrm{~Pa} \\
& \theta(t=0)=0.01 \mathrm{rad}, \dot{\theta}(t=0)=0.001 \mathrm{rad} / \mathrm{sec}
\end{aligned}
$$

Since the system comprises of highly nonlinear and stiff equations, the most appropriate Matlab solver to handle such equations is ode15s (Shampine 1994). This solver is capable of finishing the integration with the least number of steps and is considered fastest among other stiff solvers because the constant Jacobian is identified at each time step. To assess the behavior of this model and examine the presence of oscillatory motions in the ACV, some parameters that substantially affect the solution response have been identified. Three of the identified parameters that includes the ACV mass $(M)$, the entering mass flow rate in the cushion $\left(\dot{m}_{\text {in }}\right)$, and ACV base radius $(r)$ have been chosen to vary as they significantly affect the oscillatory motion of the vehicle. The other parameters are given fixed values for the sake of computations in the Matlab software.

Without loss of generality, specific ranges are assigned to the above three design parameters. These ranges are: the vehicle mass $(M)[100 \mathrm{~kg}$ to $1300 \mathrm{~kg}]$, the entering mass flow rate $\left(\dot{m}_{\text {in }}\right)[10$ $\mathrm{kg} / \mathrm{s}$ to $30 \mathrm{~kg} / \mathrm{s}$ ], and the vehicle base radius range is $[0.8 \mathrm{~m}$ to $1.0 \mathrm{~m}]$. The transient response of the $\mathrm{ACV}$ is obtained by varying the design parameters. In summary, the solution procedure is achieved using the following steps:

1. Convert the system of governing equations ((1), (2), (3), (8), and (12)) into a system of first order ordinary differential equation by state (13) to (17).

2. Adopt initial conditions equations (18) to (20) to the state space equations.

3. Use the ode15s solver in Matlab which can handle the highly nonlinear and stiff governing equations.

4. Construct the spectrums and the Poincare maps for the heave motion, pitch motion, and cusion pressure.

The numerical simulation has led to generating substantial amount of data, samples of the results are presented in Figures (3-19). Results for the heave motion are shown in Figures $(3,13)$ for two different values of the ACV base radius $r$. The heave figures show the presence of oscillatory motions. The violent oscillatory motions in the heave response in the transient stage is present and with good selection of the design parameters, these oscillations can be limited. The steady state spectrum of the heave motion is also an oscillatory motion but with small amplitude as shown in Figure (9), which indicates a clear instability in the motion of the vehicle. Figures $(4,14)$ indicates the time history of the cushion pressure. The values of the cushion pressure fluctuate about a certain value that is higher 
than the atmospheric pressure at each time step. Then its value returns to the atmospheric pressure value, which makes the mass flowrate out of the cushion volume $\dot{m}_{\text {out }}$ equal to zero. Figures $(5,6,15)$ manifest the oscillating pitch response for different values of the design parameters. One can conclude from these figures that the pitch response is not periodic when a high value of the ACV mass $(M)$ is considered.

The frequency spectrums are presented as follows: for the heave, it is shown in Figures (7-9) in light of Moon (2008) and Ghabi et al. (2018). For cushion pressure it is depicted in Figures (11, 18). Finally, for the pitch motion it presented in Figures $(12,19)$. It is evident from these figures that the self-excited response yields an excessive amount of noise. This noise which appears in the above mentioned figures represent many distinct frequency components. Figure (9) indicates the steady state spectrum of the heave motion, which shows excessive amount of damped noise of small amplitude.

Figure 3. Time history of the vertical motion (heave) for $\dot{m}_{\text {in }}=25 \mathrm{~kg} / \mathrm{s}$, and r=0.85 $\mathrm{m}$.
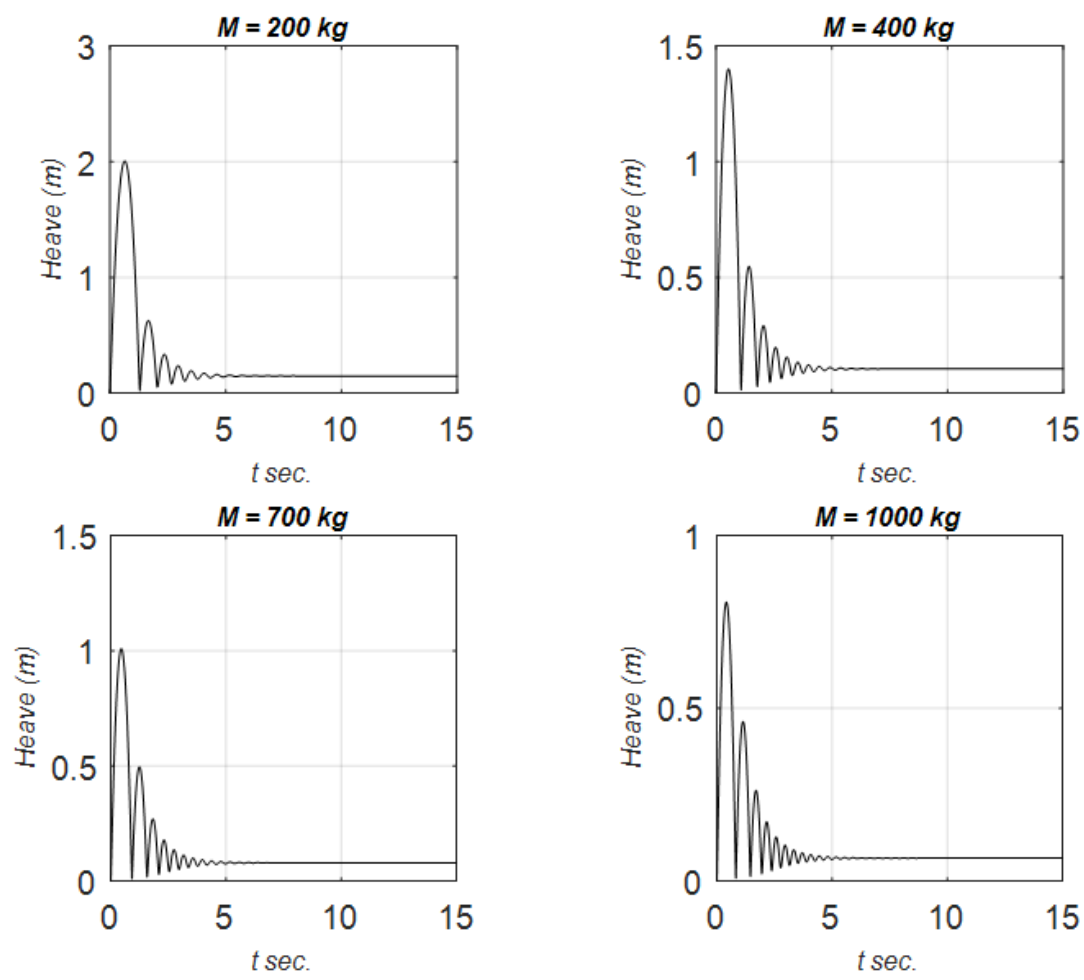
Figure 4. Cushion pressure time history for $\dot{m}_{i n}=25 \mathrm{~kg} / \mathrm{s}$, and r=0.85 m.
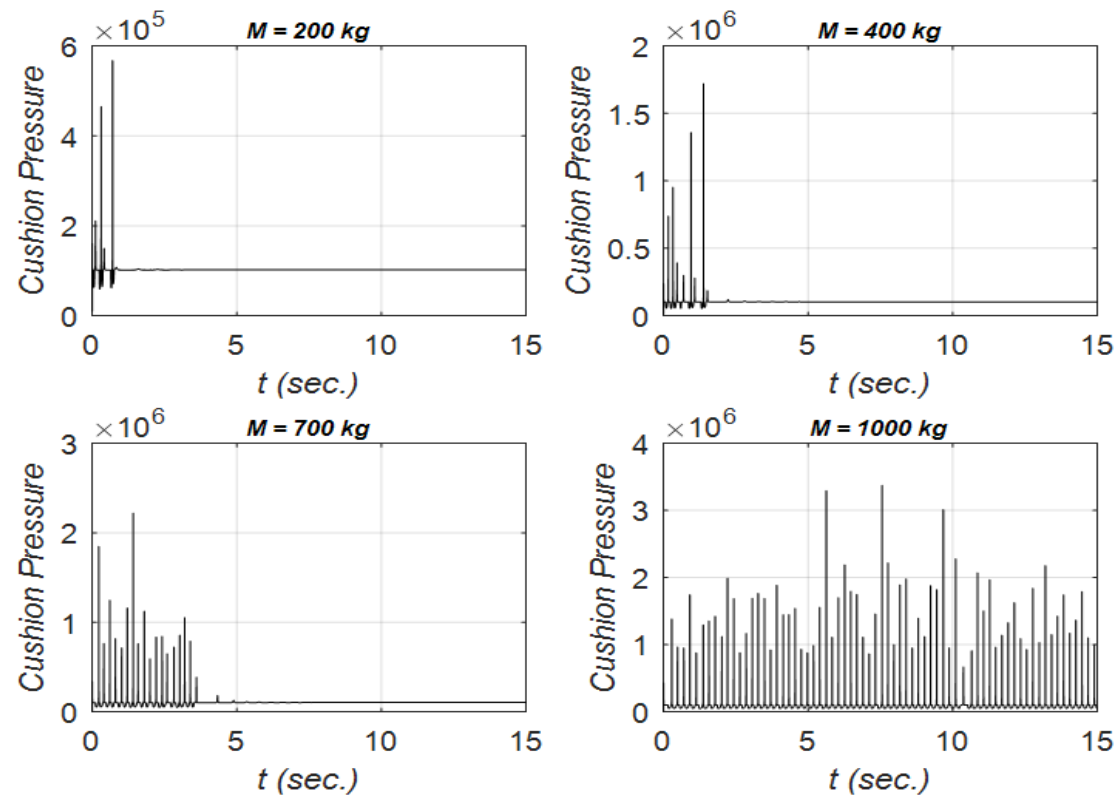

Figure 5. Pitch motion time history for $\dot{m}_{i n}=25 \mathrm{~kg} / \mathrm{s}$, and r=0.85 m.
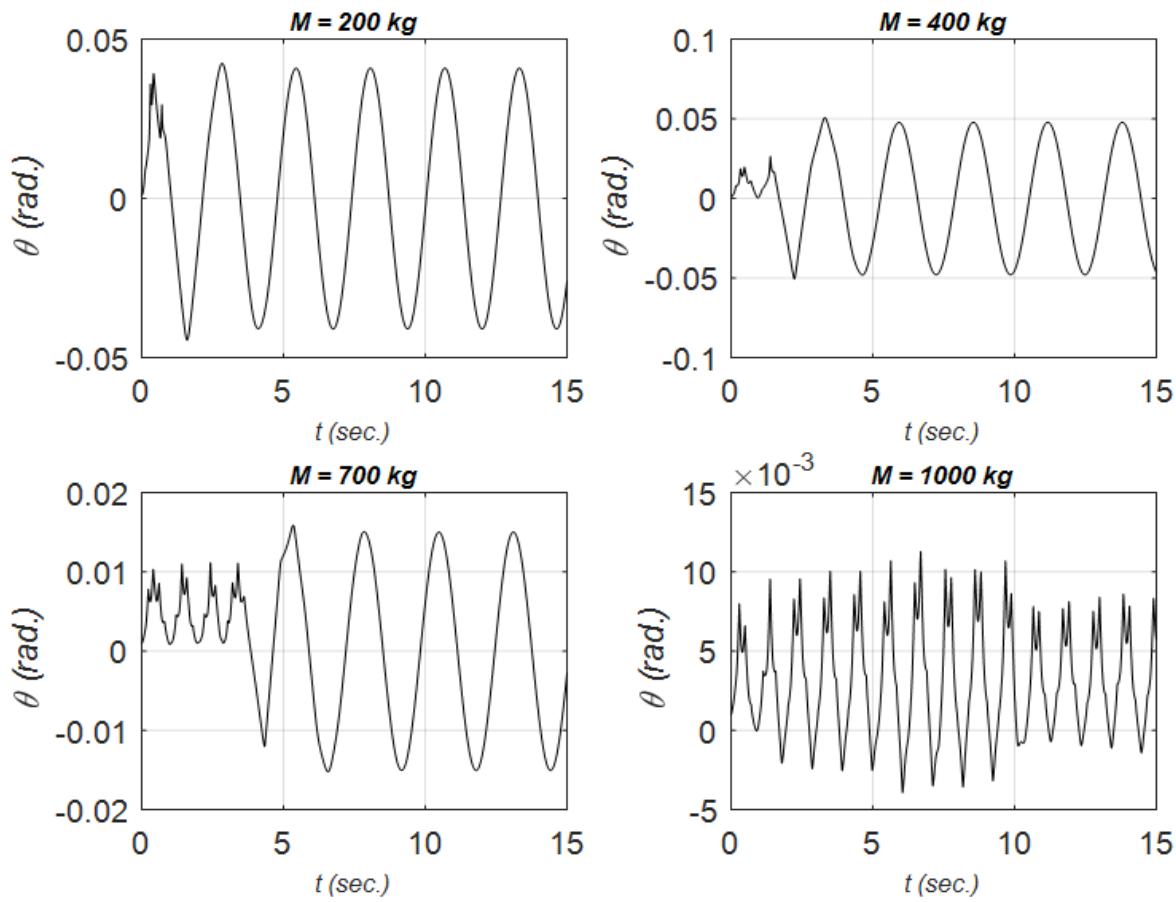
Figure 6. zoomed out pitch motion time history for $\dot{m}_{i n}=25 \mathrm{~kg} / \mathrm{s}$, and r=0.85 m.
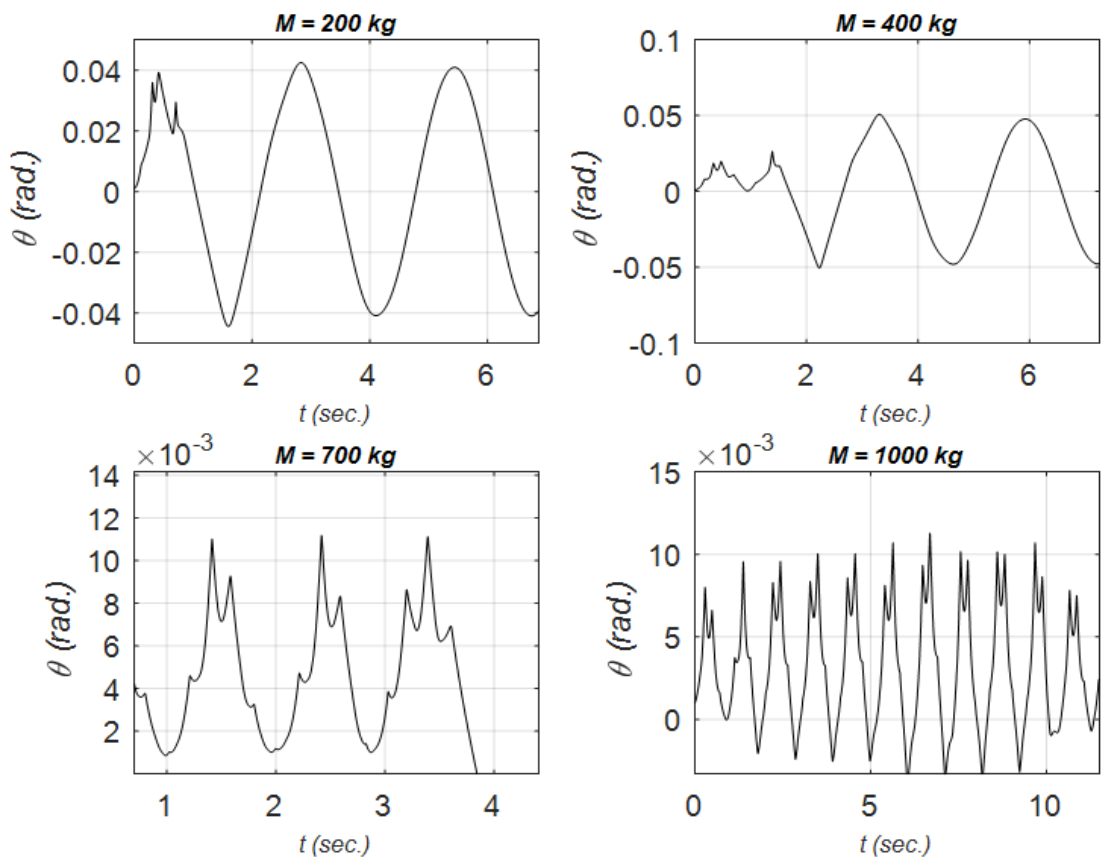

Figure 7. Spectrum of the heave response for $\dot{m}_{i n}=25 \mathrm{~kg} / \mathrm{s}$, and $\mathrm{r}=0.85 \mathrm{~m}$.
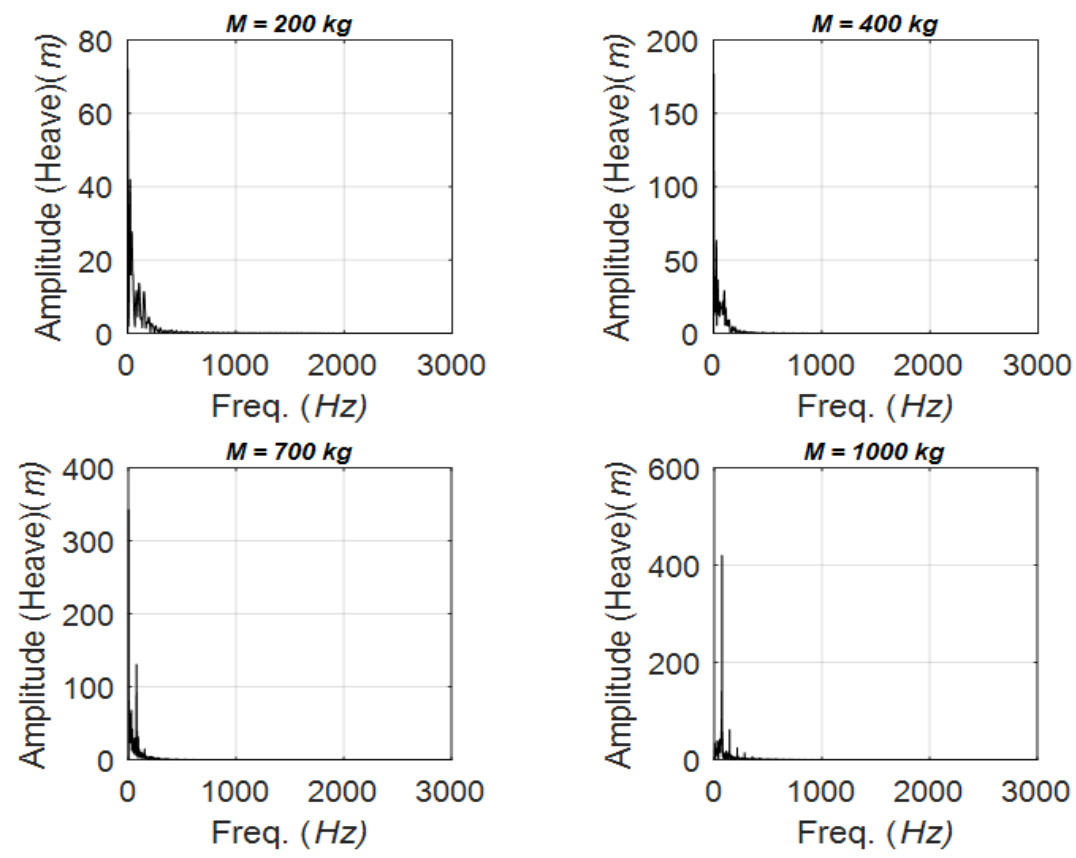
Figure 8. Zoomed in spectrum of the transient heave response for $\dot{m}_{i n}=25 \mathrm{~kg} / \mathrm{s}$, and r=0.85 m.
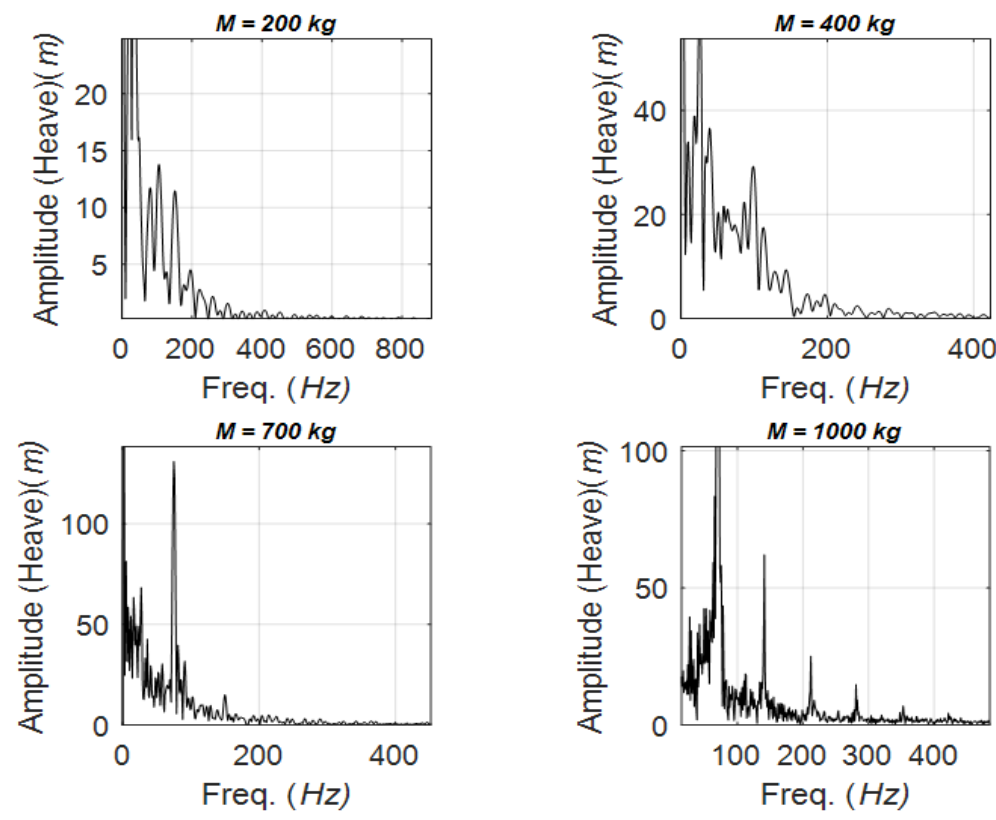

Figure 9. Spectrum of the steady state heave dynamics for $\dot{m}_{i n}=25 \mathrm{~kg} / \mathrm{s}$, and $\mathbf{r}=0.85 \mathrm{~m}$.
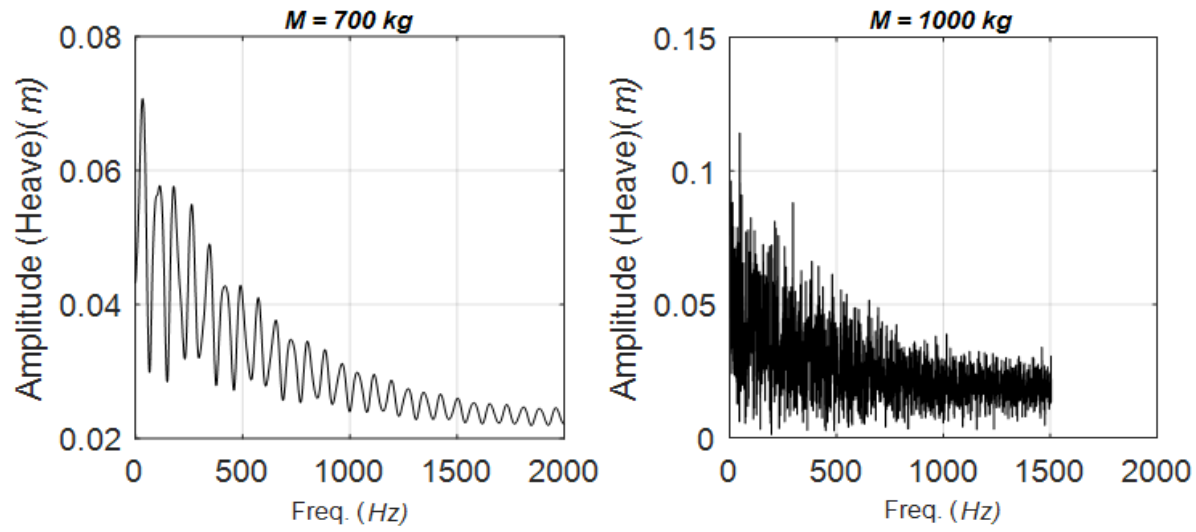
Figure 10. Heave motion sensitivity to the initial conditions for $\dot{m}_{i n}=25 \mathrm{~kg} / \mathrm{s}, \mathbf{M}=\mathbf{7 0 0 ~} \mathbf{k g}$, and r=0.85 $\mathbf{m}$.
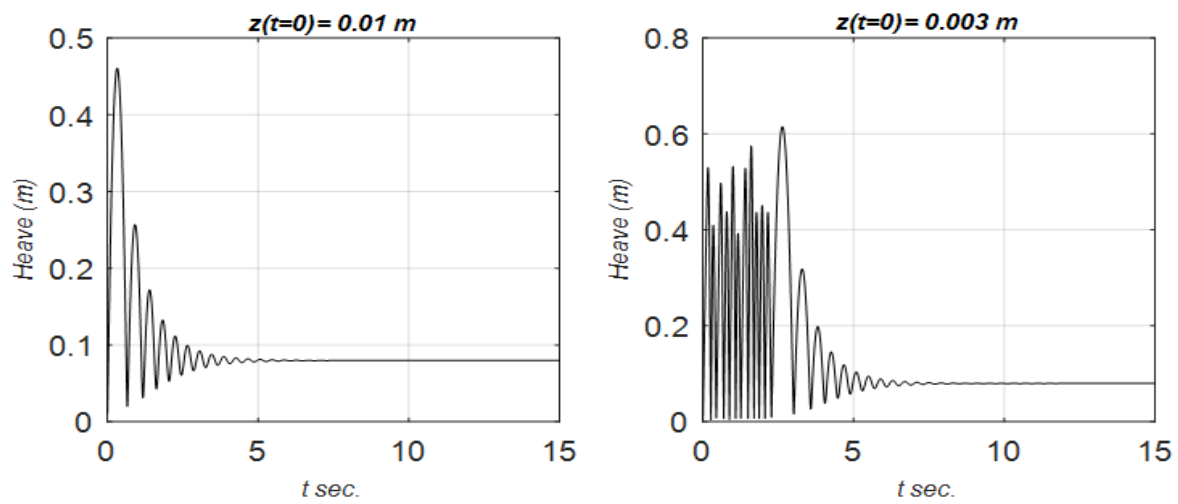

Figure 11. Spectrum of the cushion pressure for $\dot{m}_{\text {in }}=25 \mathrm{~kg} / \mathrm{s}$, and $\mathrm{r}=0.85 \mathrm{~m}$.
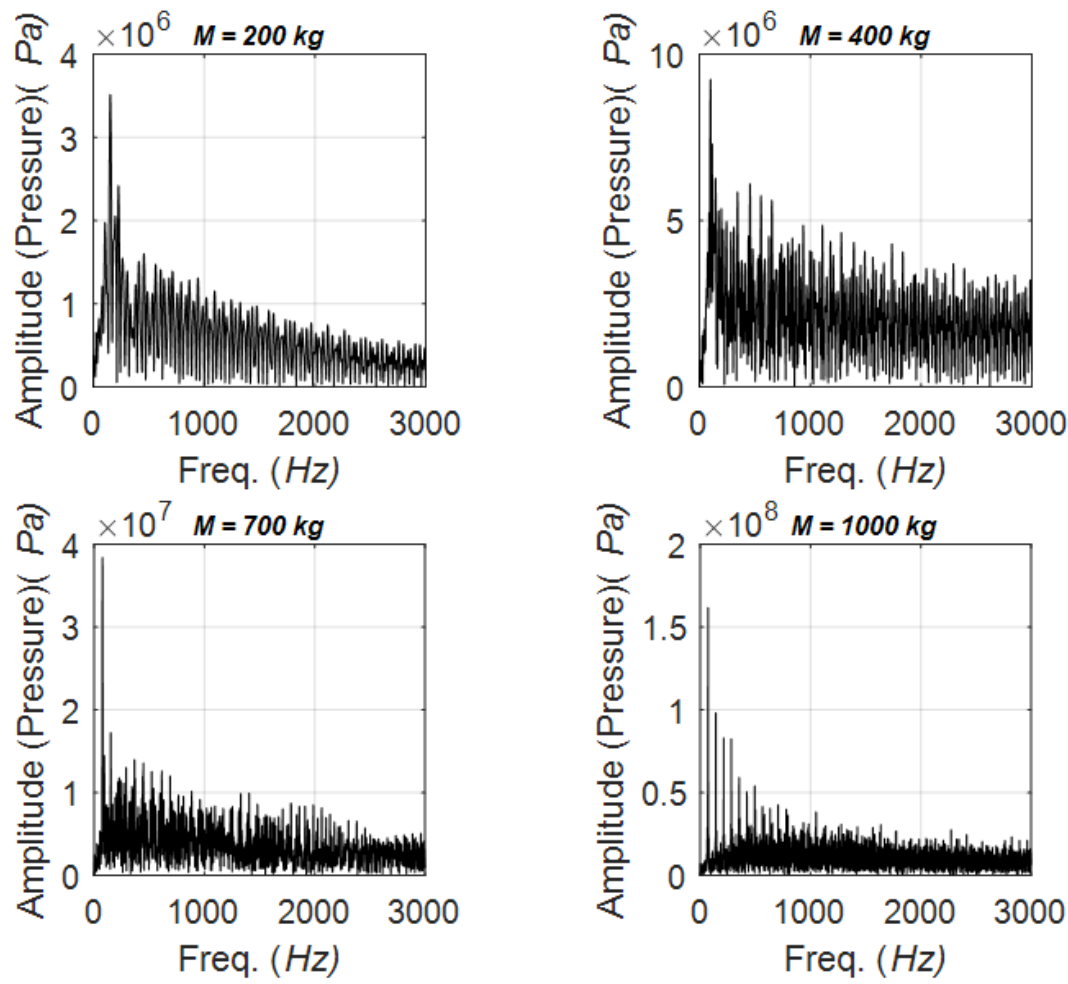
Figure 12. zoomed in pitch motion Spectrum for $\dot{m}_{i n}=25 \mathrm{~kg} / \mathrm{s}$, and $\mathbf{r}=0.85 \mathrm{~m}$.
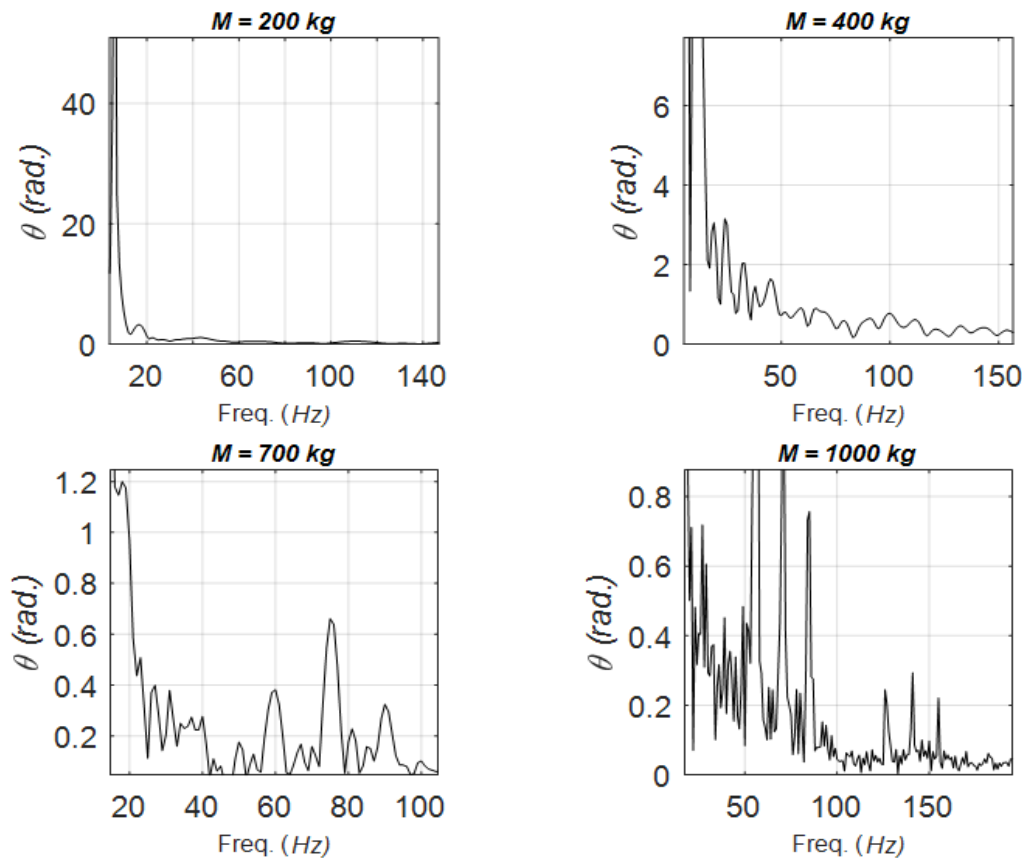

Figure 13. Time history of the vertical motion (heave) for $\dot{m}_{i n}=25 \mathrm{~kg} / \mathrm{s}$, and r=1 $\mathbf{m}$.
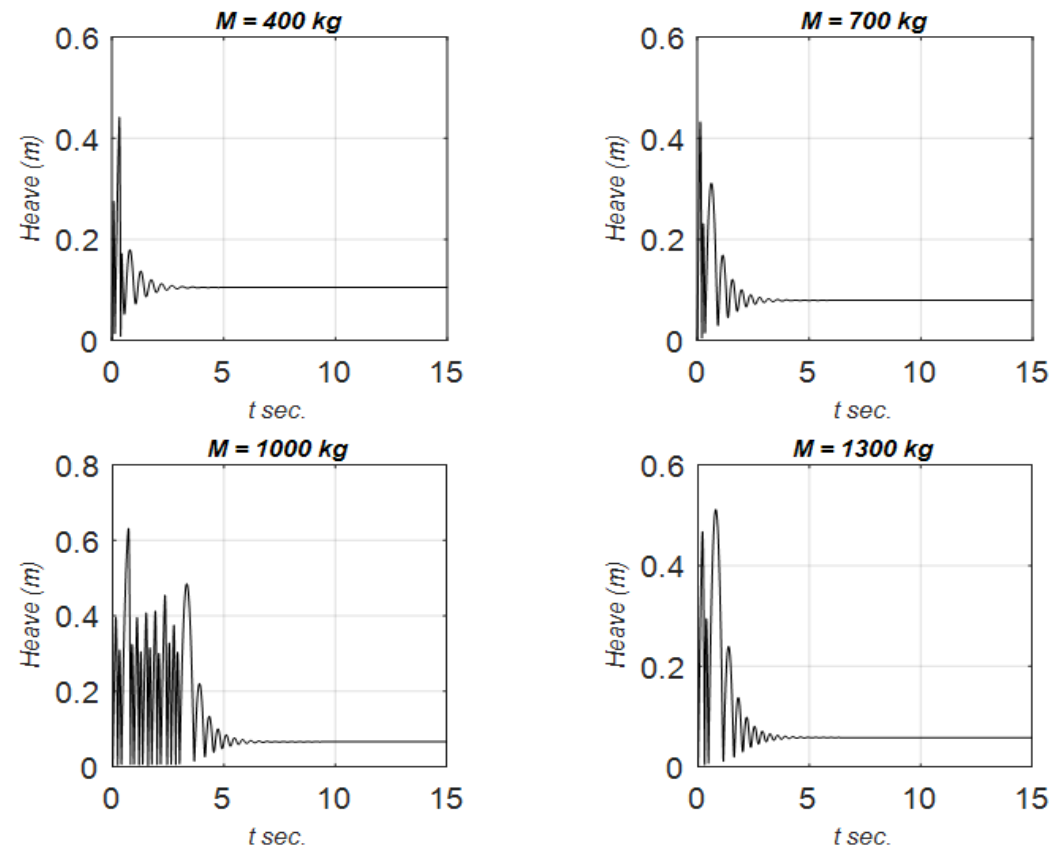
Figure 14. Cushion pressure time history for $\dot{m}_{\text {in }}=25 \mathrm{~kg} / \mathrm{s}$, and $\mathrm{r}=1 \mathrm{~m}$.
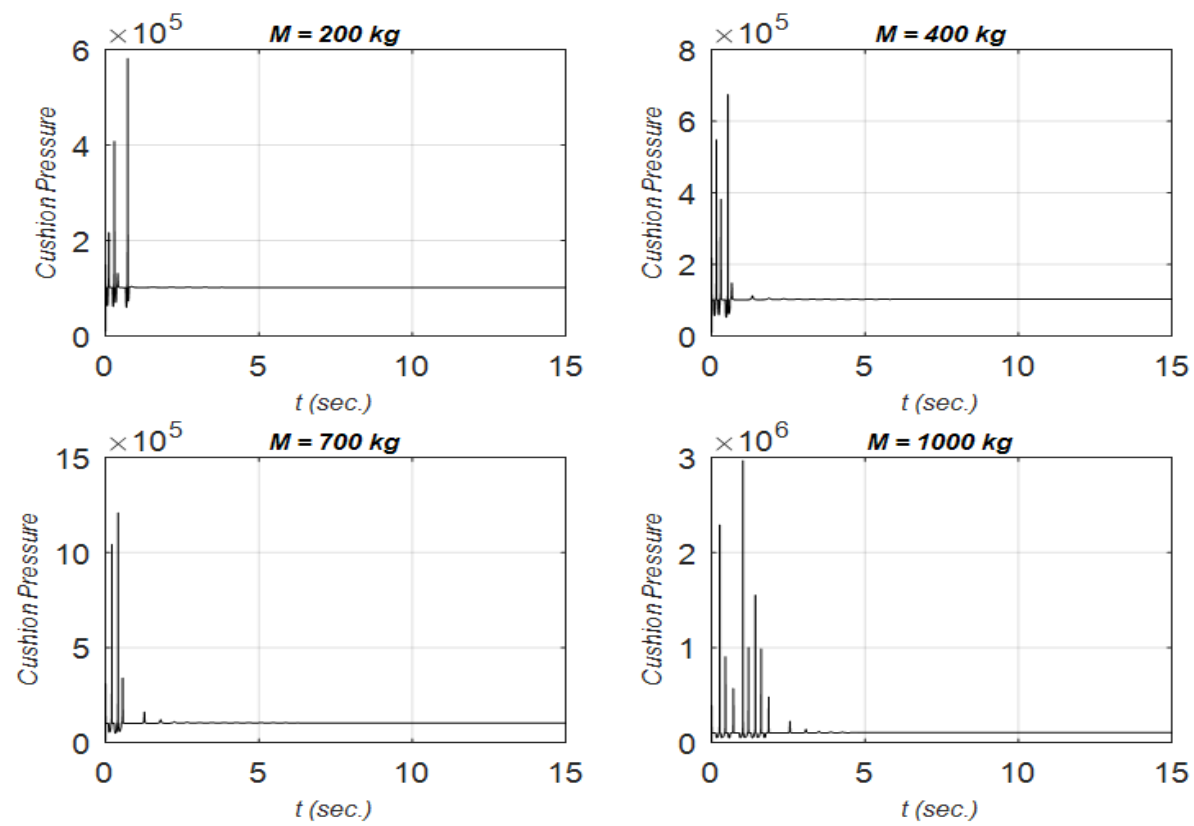

Figure 15. Pitch motion time history for $\dot{m}_{i n}=25 \mathrm{~kg} / \mathrm{s}$, and r=1 m.
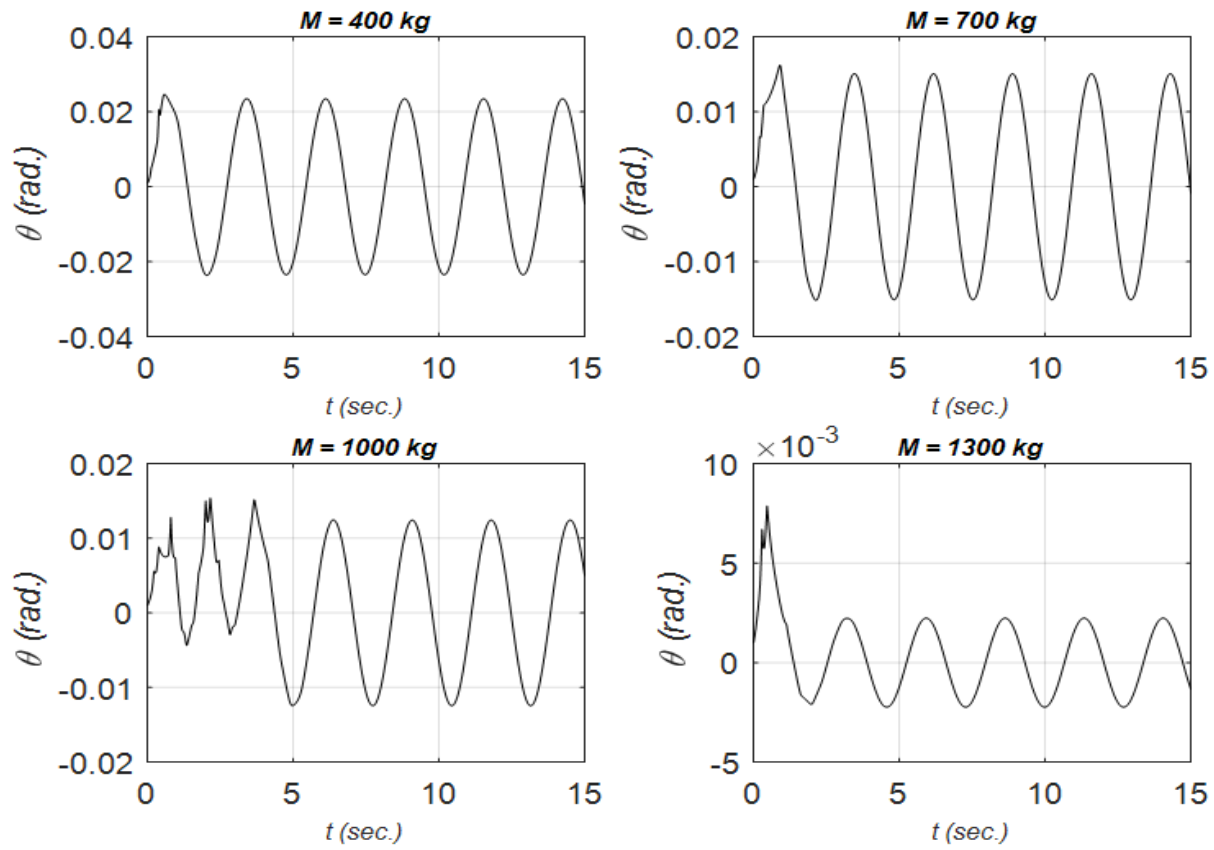
Figure 16. Spectrum of the heave dynamics for $\dot{m}_{i n}=25 \mathrm{~kg} / \mathrm{s}$, and r=1 $\mathrm{m}$.
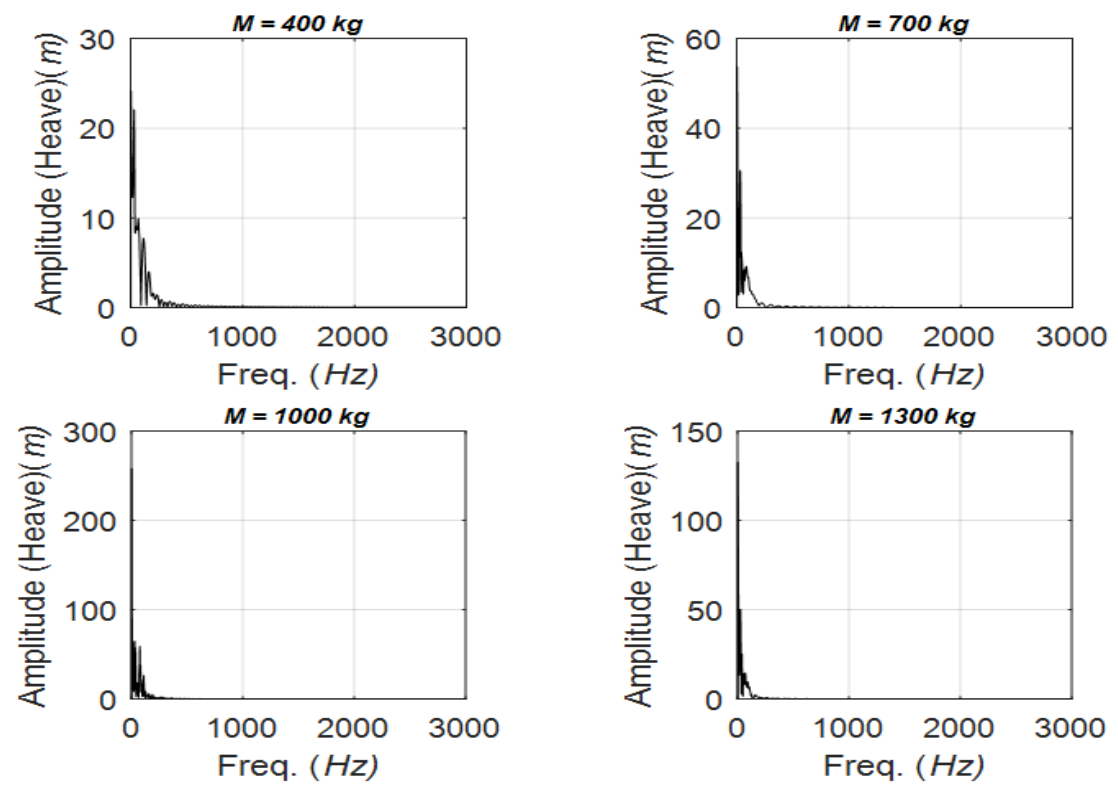

Figure 17. Zoomed in spectrum of the heave dynamics for $\dot{m}_{\text {in }}=25 \mathrm{~kg} / \mathrm{s}$, and r=1 $\mathrm{m}$.
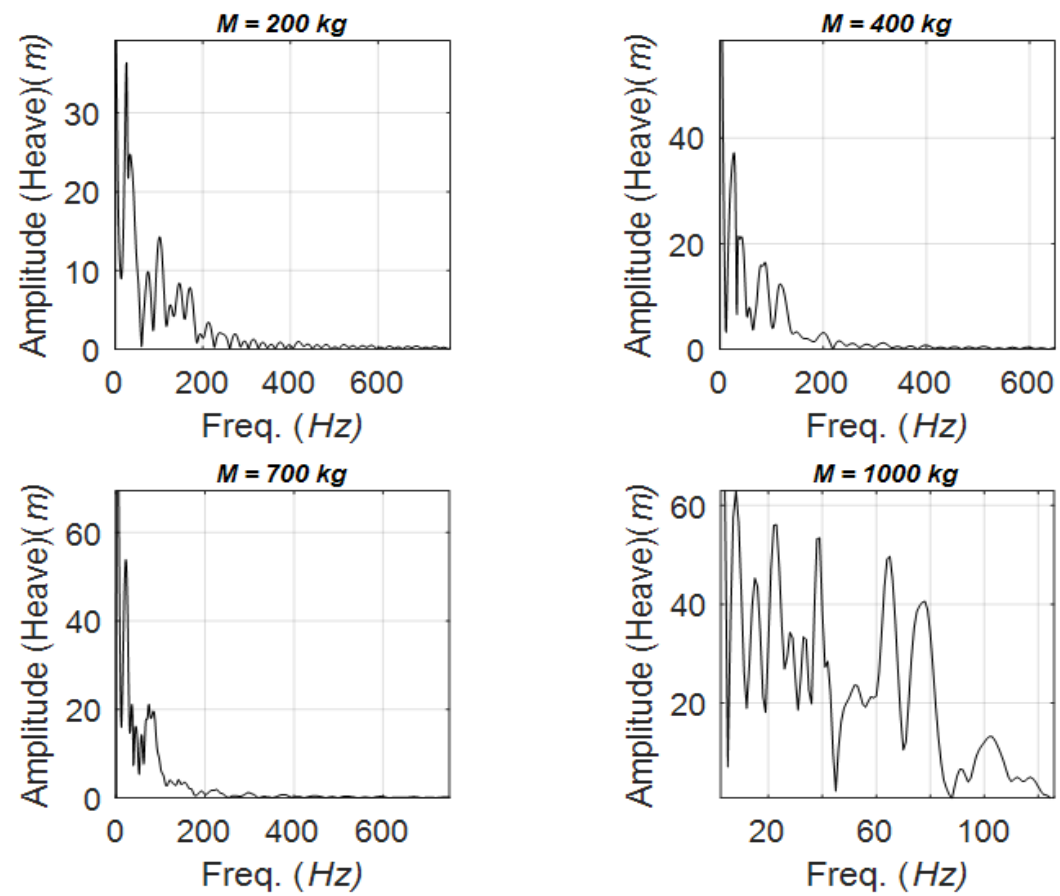
Figure 18. Spectrum of the cushion pressure for $\dot{m}_{i n}=25 \mathrm{~kg} / \mathrm{s}$, and r=1 m.
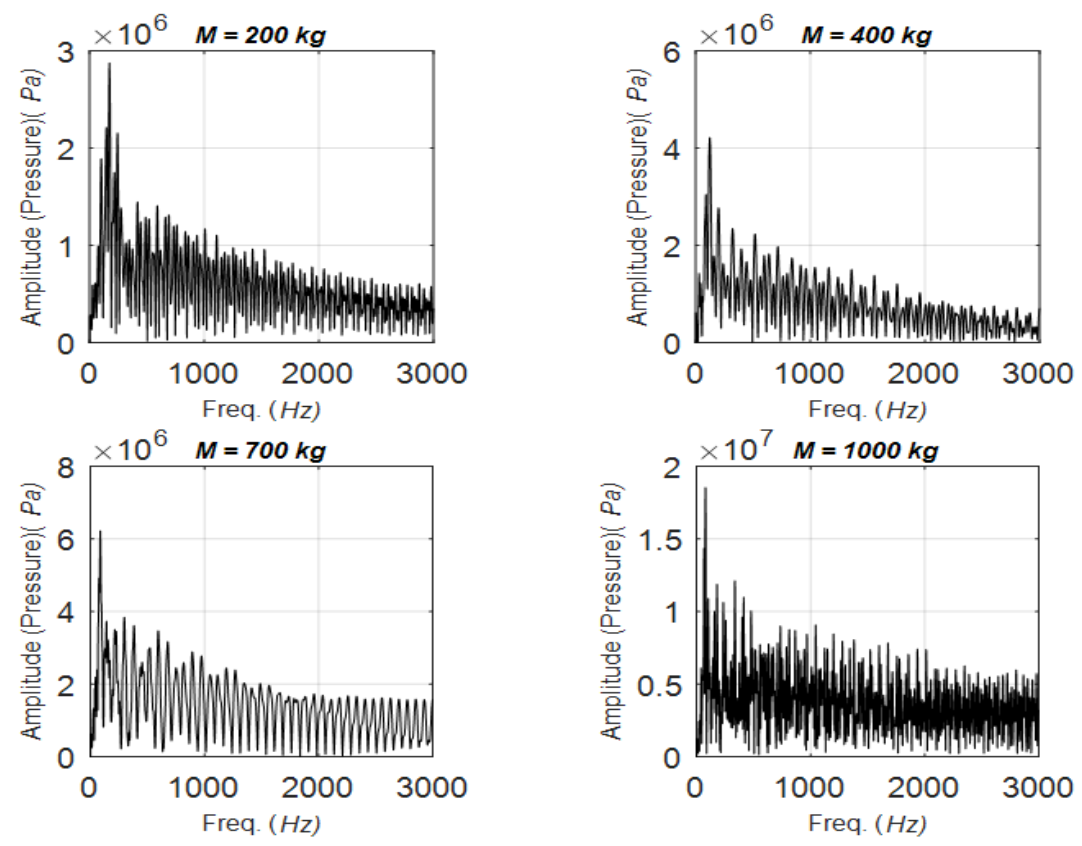

Figure 19. Pitch motion Spectrum for $\dot{m}_{i n}=25 \mathrm{~kg} / \mathrm{s}$, and $\mathrm{r}=1 \mathrm{~m}$.
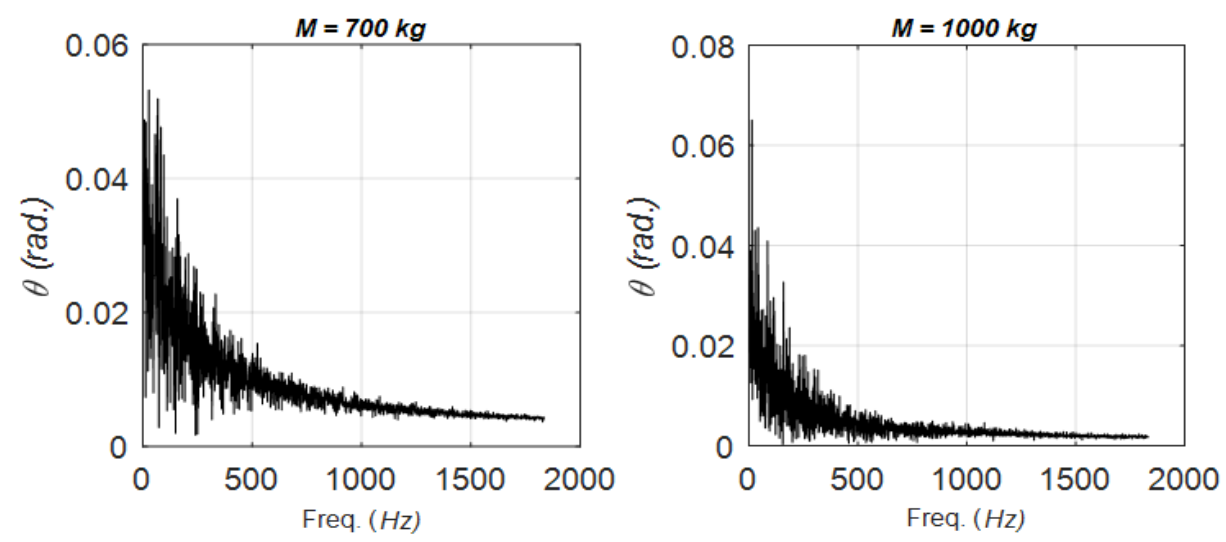


\subsection{Chaos Investigation}

The chaotic behavior of the model is investigated for the ACV's heave motion, cushion pressure, and the pitch motion. In order to observe the sensitivity of the model to the initial conditions, the chaos study requires simulations of the model for different initial conditions (Moon (2008), Thompson et al. (2002)). Two methods have been considered to identify the chaotic behavior. These methods are: the popular Fast Fourier Transform (FFT) and the Poincaré maps.

The FFT of the frequency spectrum such as the one shown in Figure (8), allows us to identify the frequency components from a noisy signal such as heave response. For example, the steady state heave response reveals a number of distinct frequencies for some design conditions in the frequency spectrum of Figure (9). The presence of large noise may be noticed also at the early transient stage for some design conditions such as those shown in Figures (16) and (17). Figure (10) indicates how sensitive of the heave motion to the initial conditions. It is clear that the heave motion is not sensitive to the initial conditions, except in the transient part of the solution. It can be concluded that the chaotic behavior of the heave motion does not exist for the range considered. Therefore, a slow damped periodic motion exists in the heave motion of the model. This will be confirmed later through the Poincaré maps as well.

The spectrum figures $(11,18)$ for the cushion pressure indicate tremendous amount of fundamental frequency (noise), confirming a definite chaotic behavior of the cushion pressure of the ACV in this model. The amplitude of the cushion pressure increases as the mass of the vehicle $(M)$ increases. On the other hand, the cushion pressure amplitude decreases as the ACV base radius increases. Figures (6) and (12) indicate the chaos behavior of the pitch motion. This will be confirmed more using the Poincaré maps.

The other method for chaos investigation is the Poincaré maps. The Poincaré maps represent the meeting of a definite lower-dimensional subspace with a periodic orbit in the state variable space of the ACV continuous dynamical conduct. By considering different values of the design parameters in the Matlab simulation, many Poincaré maps were obtained for the heave motion, cushion pressure, and the pitch motion.

In order to construct the Poincaré maps, one need to adopt certain sampling strategy for evaluating the Poincaré section. Many sampling strategies were introduced in the literature, an accepted sampling rule is to choose $t_{i}=\frac{i}{\omega_{n}}+t_{0}$, where $t_{i}$ is the time at the $i^{\text {th }}$ section, $t_{0}$ is the initial time, $\omega_{n}$ is the first fundamental frequency which can be achieved from the spectrum response, and $i$ is the number of sampling points (Moon (2008), Thompson et al. (2002)).

Samples of the Poincaré maps are presented in Figures (20-25). After reviewing the presented Poincaré maps, the chaotic behavior was confirmed for both the cushion pressure and the pitch motion for some values of the design parameters. This happens mostly when the design parameters have non-uniform values relative to each other. For example, in the range considered in this study, when the vehicle mass $(M)$ is high, the vehicle base radius $r$ is low and the mass flow rate $\dot{m}_{\text {in }}$ is also high, the chaotic behavior is present for the cushion pressure as confirmed by the spectrum figures. The chaotic behavior arising from the pitch motion is confirmed from Figures $(6,12,22,25)$. This is because the arrangements of the points of the Poincaré maps (wright) in Figures (24-25), for example, is different in the sampled Poincare maps (left). On the other hand, same arrangements of the points in both the Poincaré and Poincaré sampled maps for the heave motion as shown in Figures (20) and (23), which suggests a non-chaotic heave motion for the ACV.

The heave dynamics showed a periodic damped response for some design parameters. At the start of the transient response some irregular harmonics are observed in the heave response. Figure (15) indicated some large noise for high vehicle mass $(M)$ in the early stage of the transient heave response. This may allow one to conclude the lack of presence of chaos in the heave motion. This 
is confirmed by having a different Poincaré map by slightly altering the initial conditions, a closed orbit of regular motion is present as shown in Figures (20) and (22).

Figures (23) to (25) represent the Poincaré maps for different initial conditions. A clear change especially for the cushion pressure and the pitch motion is noticed in the Poincaré maps when a small change in initial conditions is considered. The changes for the cushion pressure with different initial conditions may be seen by comparing Figures (21) and (24), while Figures (22) and (25) may be compared to observe the changes for the pitch motion. Figure (22) indicates a strange chaotic attractor for the complete pitch motion.

This study is a continuation for the study to our previous work Sowayan et al. (2012) and Sowayan et al. (2013), where in these studies only heave motion was considered in modelling the ACV. Obviously, adding the pitch degree of freedom to the current study increase the complexity of the problem. Therefore, in the current study a strong interaction between the pressure forces and the pitching motion were encountered. Also, the dynamics behavior of the model in this study becomes less stable and chaotic motion is observed.

The heave Poincaré maps in Figures (20) and (23) indicate closed curve with a quasi-periodic heave motion indicating a large amount of oscillatory motion, which is not preferable for the ACV heave motion. Chaotic behavior of the cushion pressure may accelerate the failure of the cushion volume due to the inconsistency of the magnitudes of the body forces inside the vehicle cushion volume. The cushion pressure portrait on the Poincaré map Figure (21) is a closed curve, but when changing the initial conditions in Figure (24) a strange attractor is followed.

It may be seen from Figures (22) and (25) that the phase trajectories of the pitch motion are complicated, irregular, and the structure of its points has no rules. These Poincare maps of the pitch motion reveal chaos movements which result in having unstable azimuthal motion for the ACV. This can cause a body discomfort for the rider of these vehicles.

Figure 20. Heave motion: (a) Poincaré map (b) sampled Poincaré map, for $\dot{m}_{i n}=15 \mathrm{~kg} / \mathrm{s}, \mathbf{M}=700 \mathbf{k g}$, and r=0.75 m, $z(t=0)=0.001 \mathrm{~m}$.
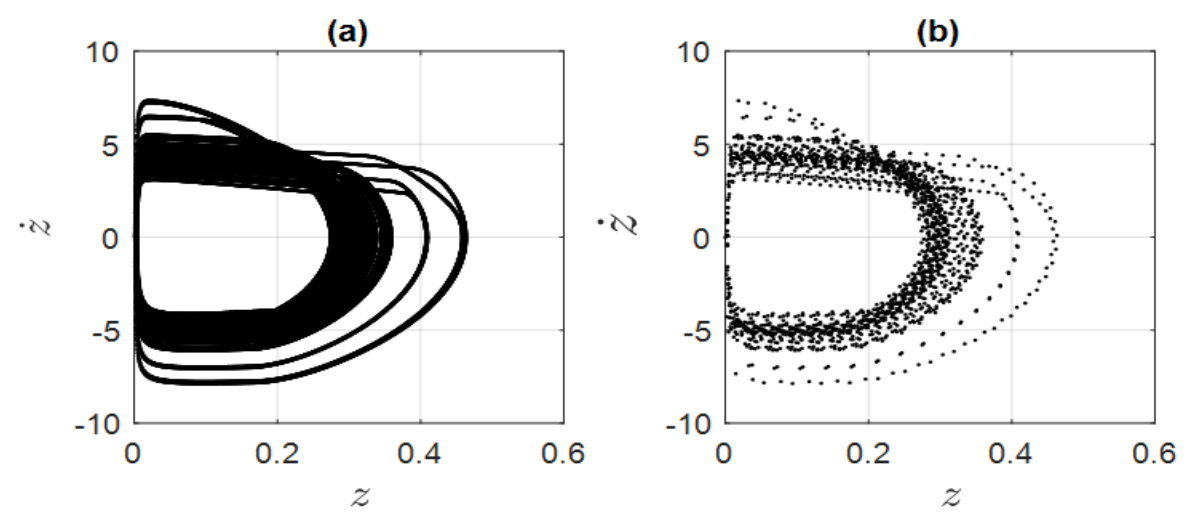
Figure 21. Cushion pressure: (a) Poincaré map (b) sampled Poincaré map, for $\dot{m}_{i n}=15 \mathrm{~kg} / \mathrm{s}, \mathbf{M = 7 0 0 ~} \mathbf{k g}$, and r=0.75 m, $z(t=0)=0.001 \mathrm{~m}$.
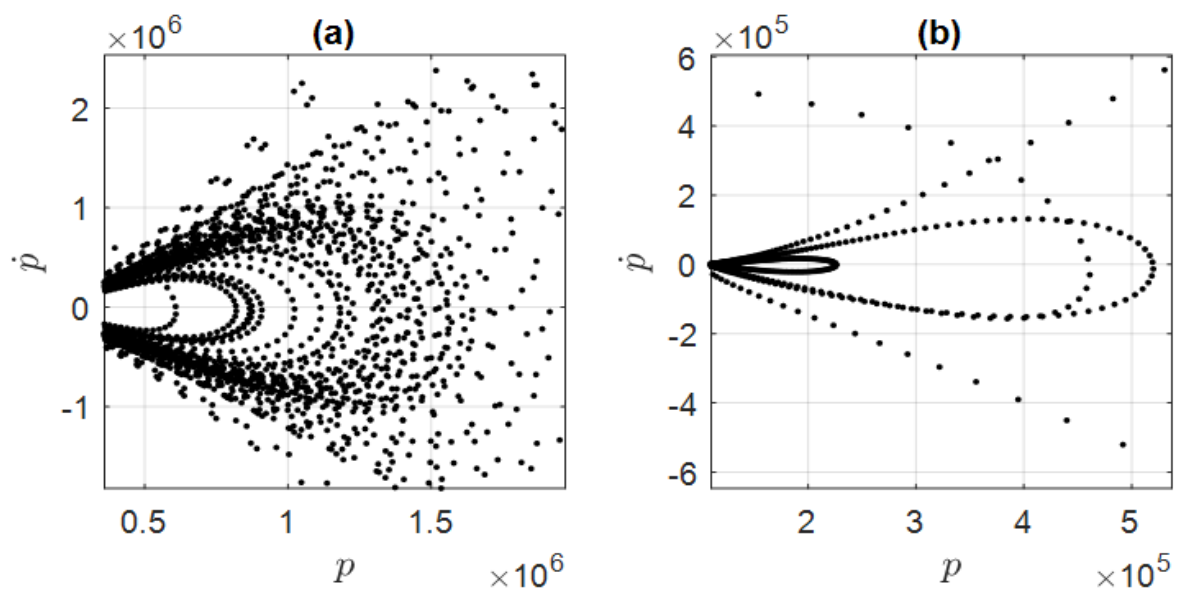

Figure 22. Pitch motion: (a) Poincaré map (b) sampled Poincaré map, for $\dot{m}_{i n}=15 \mathrm{~kg} / \mathrm{s}, \mathrm{M}=\mathbf{7 0 0 ~ k g}$, and r=0.75 m, $\mathbf{z}(\mathrm{t}=0)=0.001$ m.

(a)

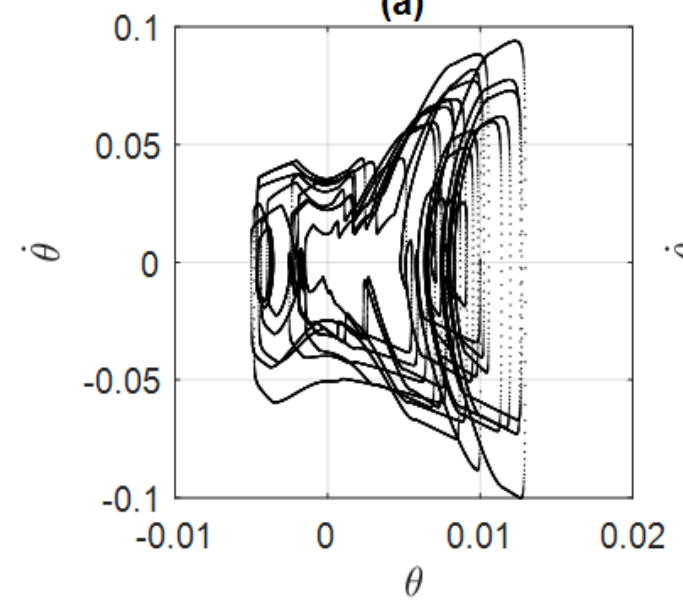

(b)

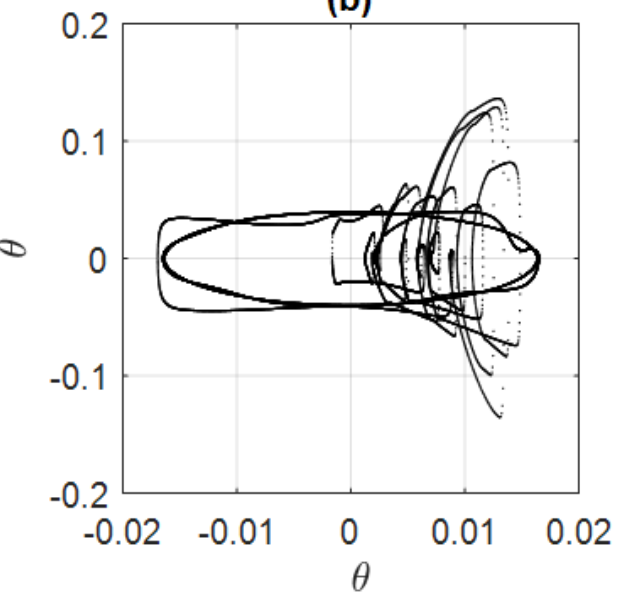


Figure 23. Heave motion: (a) Poincaré map (b) Poincaré section, for $\dot{m}_{i n}=15 \mathrm{~kg} / \mathrm{s}, \mathbf{M}=\mathbf{7 0 0} \mathrm{kg}$, and r=0.75 $\mathrm{m}, \mathbf{z}(\mathrm{t}=\mathbf{0})=0.007$ m.

(a)

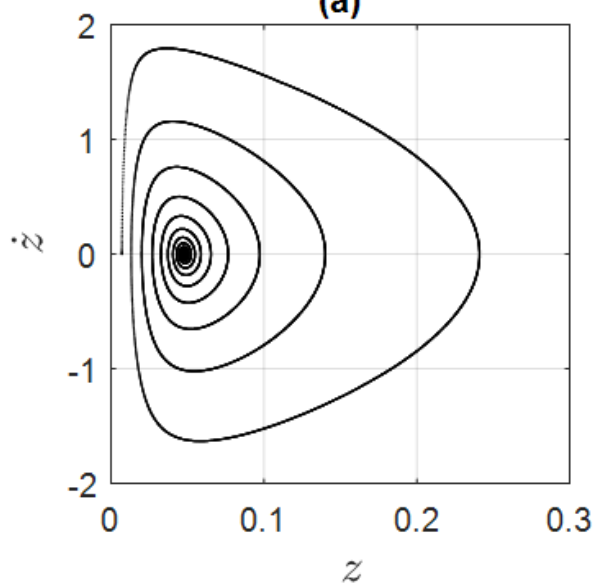

(b)

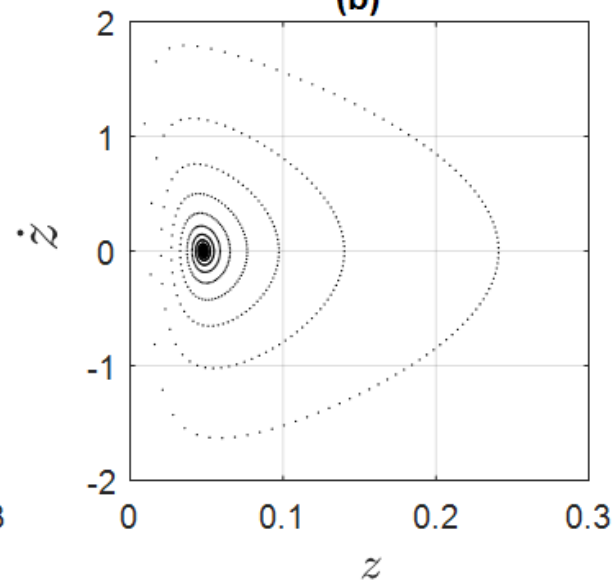

Figure 24. Cushion pressure: (a) Poincaré map (b) sampled Poincaré map, for $\dot{m}_{i n}=15 \mathrm{~kg} / \mathrm{s}, \mathbf{M}=700 \mathrm{~kg}$, and r=0.75 m, $z(t=0)=0.007 \mathrm{~m}$.

(a)

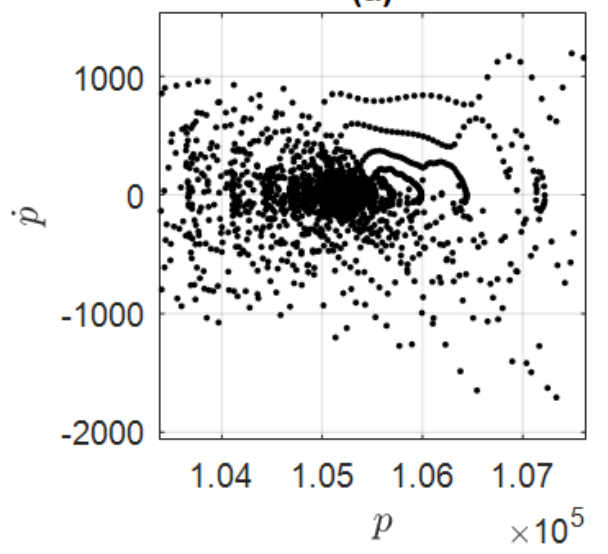

(b)

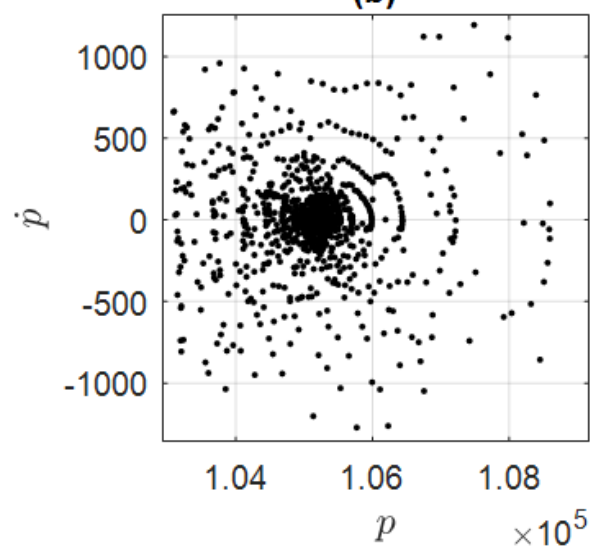



m.

(a)

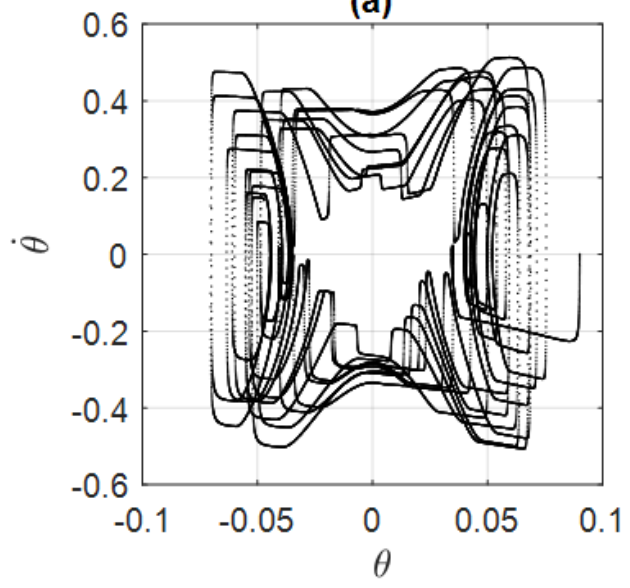

(b)

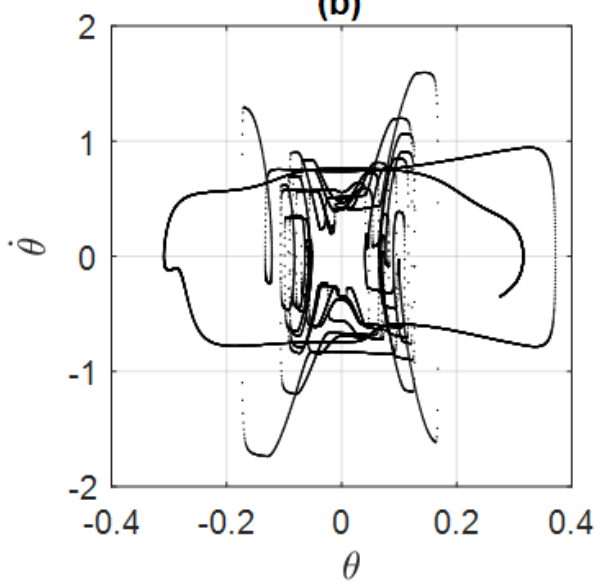

\section{CONCLUSION}

A highly nonlinear model for the dynamic behavior of the heave and pitch motions of ACV is considered in this study. The model is based on the Newton's second law of translation and rotation, and the basics of thermodynamics and fluid mechanics. The nonlinearity of the model arises due to the presence of the polytropic exponent in the governing equations, which results in making the model self-excited. The dynamic behavior of the ACV is numerically studied using the ode stiff solvers provided in the Matlab software. Results obtained from the Matlab numerical simulations include the estimation of heave motion, vertical velocity, cushion pressure, angular rotation, and angular velocity in the pitching direction.

Also the chaos motion of this model is investigated for all dependent variables, and for some other design parameters. Three of the design parameters have been found to have a significant effect on chaotic behavior of the model. These are: mass of the vehicle $M$, the vehicle base radius $r$, and air mass flowrate into the cushion volume $\dot{m}_{\text {in }}$. The model is tested for the sensitivity of the initial conditions, and it is found to be sensitive the cushion pressure, and the pitch motion. Damped periodic harsh oscillatory motion was encountered for the ACV heave motion. The FFT spectrum and the Poincaré maps indicated a chaotic behavior of the model for the cushion pressure, and the pitch motion. Uninterrupted oscillations in the cushion pressure and pitch motion are observed.

\section{NOMENCLATURE}

$\mathrm{M}=$ Mass of the vehicle $(\mathrm{kg})$

I $=$ ACV moment of inertia $(\mathrm{kg} \mathrm{m} 2)$

$\mathrm{L} \quad=$ Skirt length $(\mathrm{m})$

$\mathrm{h}=$ Metacenter distance $(=0.15 \mathrm{~m})$

$\mathrm{d}=\mathrm{ACV}$ height from ground $(0.008 \mathrm{~m})$ 
$\mathrm{z} \quad=$ Heave displacement $(\mathrm{m})$

$z=$ Vertical acceleration $\left(\mathrm{m} / \mathrm{s}^{2}\right)$

$p_{a}=$ Atmospheric pressure $(101000 \mathrm{~Pa})$

$\dot{p}=$ Cushion pressure $(\mathrm{Pa})$

$\theta=$ Pitch angular displacement (Radian)

$\dot{\theta}=$ Angular velocity of the ACV ( $\mathrm{rad} / \mathrm{sec})$

$\mathrm{r} \quad=$ Radius of the ACV base (m)

$\mathcal{M}_{G}=$ Moment about center of mass (N.m)

$F_{M}=$ force due to the momentum flow (N)

$\mathrm{A}=\mathrm{ACV}$ base area $(\mathrm{m} 2)$

$A_{e}=$ Exit area $\left(\mathrm{m}^{2}\right)$

$\gamma=$ Specific heat ratio $\left(c_{p} / c_{v}\right)$

$\mathrm{R}=$ Gas constant

$\mathrm{T}=$ Temperature of air $(298 \mathrm{~K})$

$g=$ Gravitational acceleration $\left(9.81 \mathrm{~m} / \mathrm{s}^{2}\right)$

$\rho=$ Air cushion density $\left(\mathrm{kg} / \mathrm{m}^{3}\right)$

$\rho_{a}=$ Atmospheric Air density $\left(1.189 \mathrm{~kg} / \mathrm{m}^{3}\right)$

$c_{0}$ Correction coefficient factor $(=0.7)$

$\mathrm{V}=$ Cushion volume $\left(\mathrm{m}^{3}\right)$

$\mathrm{m}=$ Mass of air inside the cushion volume $(\mathrm{kg})$

$\dot{m}=$ Mass flow rate of air $(\mathrm{kg} / \mathrm{s})$

$\dot{m}_{i n}=$ Mass flow rate of air inside the cushion volume $(\mathrm{kg} / \mathrm{s})$

$\dot{m}_{\text {out }}=$ Mass flow rate of air outside the cushion volume $(\mathrm{kg} / \mathrm{s})$

\section{ACKNOWLEDGMENT}

The author would like to thank Al Imam Mohammad Ibn Saud Islamic University for its support and use of the University facilities to conduct this study. 


\section{REFERENCES}

Ab Rashid, M. Z., Shah, H. N. M., Othman, M. N., Aras, M. S. M., Sulaiman, M., \& Latif, M. F. A. (2017). Parameter Estimation and Verification of Unmanned Air Cushion Vehicle (UACV) System. In MATEC Web of Conferences (Vol. 97, p. 01069). EDP Sciences.

Balochian, S., \& Rajaee, N. (2018). Fractional-Order Optimal Control of Fractional-Order Linear Vibration Systems with Time Delay. International Journal of System Dynamics Applications, 7(3), 72-93. doi:10.4018/ IJSDA.2018070104

Bliault, A. (2000). Theory and design of air cushion craft. John Wiley \& Sons Inc.

Chung, J. (2002). Skirt-material damping effects on heave dynamics of an air-cushion-vehicle bag-and-finger skirt. Canadian Aeronautics and Space Journal, 48(3), 201-212. doi:10.5589/q02-025

Chung, J., \& Jung, T. C. (2004). Optimization of an air cushion vehicle bag and finger skirt using genetic algorithms. Aerospace Science and Technology, 8(3), 219-229. doi:10.1016/j.ast.2003.11.002

Chung, J., \& Sullivan, P. A. (2000). Linear heave dynamics of an air-cushion vehicle bag-and-finger skirt. Transactions of the Japan Society for Aeronautical and Space Sciences, 43(140), 39-45. doi:10.2322/tjsass.43.39

Eremeyev, V. O., Peplin, F. S., \& Tumanin, A. V. (2017). Mathematical Model of Dynamics of Air Cushion Vehicle with Ballonet Type Skirt on Water. Procedia Engineering, 206, 354-359. doi:10.1016/j.proeng.2017.10.485

Fu, M., Wang, T., \& Wang, C. (2019). Barrier Lyapunov function-based adaptive control of an uncertain hovercraft with position and velocity constraints. Mathematical Problems in Engineering, 2019, 2019. doi:10.1155/2019/1940784

Ghabi, J., Rhif, A., \& Vaidyanathan, S. (2018). Discrete Time Sliding Mode Control Scheme for Nonlinear Systems With Bounded Uncertainties. International Journal of System Dynamics Applications, 7(2), 15-33. doi:10.4018/IJSDA.2018040102

Graham, T. A., \& Sullivan, P. A. (2002). Pitch-heave dynamics of a segmented skirt air cushion. Journal of Ship Research, 46(2), 121-137.

Han, Y., \& Liu, X. (2016). Higher-order sliding mode control for trajectory tracking of air cushion vehicle. Optik (Stuttgart), 127(5), 2878-2886. doi:10.1016/j.ijleo.2015.11.180

Hossain, A., Rahman, A., Mohiuddin, A. K. M., \& Aminanda, Y. (2011). Dynamic modeling of intelligent aircushion tracked vehicle for swamp peat. International Journal of Aerospace and Mechanical Engineering, 5(4). Advance online publication. doi:10.4271/2011-01-0088

$\mathrm{Ji}$, N. (2012, June). Motion simulation of air cushion vehicle in beach-landing. In Fourth International Conference on Digital Image Processing (ICDIP 2012) (Vol. 8334, p. 83343J). International Society for Optics and Photonics. doi:10.1117/12.966363

Jung, T. C., \& Eng, B. (2002). Design of air cushion vehicles using artificial intelligence: Expert system and genetic algorithm. Masters Theses. Ryerson University.

Lavis, D. R. (2011). Fifty years \& more of hovercraft development. International Conference on Air Cushion Vehicles and Surface Effect Craft, 1-46.

Milewski, B., Connell, B., Wilson, J., \& Kring, D. (2007). Dynamics of air cushion vehicles operating in a seaway. 9th International Conference on Numerical Ship Hydrodynamics, 1-15.

Milewski, W., Connell, B., Petersen, B., \& Kring, D. (2008, October). Initial validation of the ACVSIM model for dynamics of air cushion vehicles. In Proceedings of the 27th Symposium on Naval Hydrodynamics (pp. 5-10). Academic Press.

Moon, F. C. (2008). Chaotic and fractal dynamics: introduction for applied scientists and engineers. John Wiley \& Sons.

Nayfeh, A. H. (2011). Introduction to perturbation techniques. John Wiley \& Sons. 
Nikseresht, A. H., Alishahi, M. M., \& Emdad, H. (2008). Complete flow field computation around an ACV (air-cushion vehicle) using 3D VOF with Lagrangian propagation in computational domain. Computers \& Structures, 86(7-8), 627-641. doi:10.1016/j.compstruc.2007.08.006

Pollack, M., Connell, B., Wilson, J., \& Milewski, W. (2007, January). Dynamic Modeling of Air Cushion Vehicles. In ASME International Mechanical Engineering Congress and Exposition (Vol. 43025, pp. 16931698). Academic Press.

Shampine, L. F. (1994). Numerical solution of ordinary differential equations. CRC Press.

Sowayan, A. S., \& AlSaif, K. A. (2012). Modeling of the transient response for compressible air cushion vehicles (acv). Applied Mechanics and Materials, 152, 560-567. doi:10.4028/www.scientific.net/AMM.152-154.560

Sowayan, A. S., \& AlSaif, K. A. (2013). Investigation of the heave dynamics of Air Cushion Vehicles (ACV): Parametric and chaotic studies. Latin American Journal of Solids and Structures, 10(4), 725-745. doi:10.1590/ S1679-78252013000400004

Thompson, J. M. T., \& Stewart, H. B. (2002). Nonlinear dynamics and chaos. John Wiley \& Sons.

Trikha, P., \& Jahanzaib, L. S. (2020). Dynamical Analysis of a Novel 4-D Hyper-Chaotic System With One Non-Hyperbolic Equilibrium Point and Application in Secure Communication. International Journal of System Dynamics Applications, 9(4), 74-99. doi:10.4018/IJSDA.2020100104

Wang, Y., \& Tong, H. (2017, September). Second order nonsingular terminal sliding mode control with extended state observer for course control of air cushion vehicle. In OCEANS 2017-Anchorage (pp. 1-7). IEEE.

White, F. M., \& Corfield, I. (2006). Viscous fluid flow (Vol. 3). McGraw-Hill.

Xie, D., Ma, C., \& Luo, Z. (2012). Research on air-cushion system test and simulation of semi-track air-cushion vehicle. Jixie Gongcheng Xuebao, 48(4), 120-128. doi:10.3901/JME.2012.04.120

Xu, S., Tang, Y., Chen, K., Zhang, Z., Ma, T., \& Tang, W. (2020). Numerical investigation on pressure responsiveness properties of the skirt-cushion system of an air cushion vehicle. International Journal of Naval Architecture and Ocean Engineering, 12, 928-942. doi:10.1016/j.ijnaoe.2020.09.006

Xu, S., Zhang, Z., Gao, X., Ma, T., \& Tang, W. (2019, July). The Study of Configuration Optimization for Air Cushion Vehicle Skirt Based on CATIA-Abaqus Parametric Finite Element Method. In The 29th International Ocean and Polar Engineering Conference. International Society of Offshore and Polar Engineers.

Zhang, H., \& Nanji, L. (2012). Modeling and simulation of air cushion vehicle 6-DOF maneuverability. International Journal of Digital Content Technology and its Applications, 214-222.

Ahmed S. Sowayan got his PhD in Mechanical Engineering in August of 1999 from Michigan State University, East Lansing, Michigan. In June of 1995 he received his MSc. in Mechanical Engineering from Western Michigan University, Kalamazoo, Michigan. In December of 1989 he finished his BSc. in Mechanical Engineering from King Saud University Riyadh, Saudi Arabia. His field of interests in research and teaching include computational and analytical heat transfer/fluid mechanics problems, Compressors, Vibrations of rotating and non-rotating bodies, Viscoelastic fluid flow, Refrigeration and air conditioning, Material testing, Combustion. He worked in many places in the kingdom of Saudi Arabia, for example, he worked as a consultant in the General Directorate of Equivalency in Ministry of Higher Education, Riyadh, Saudi Arabia. He also worked as a consultant at the King Abdullah Scholarship Program (KASP) in the Ministry of Higher Education, Riyadh, Saudi Arabia. He was also appointed as a vice dean at the Riyadh College of Technology, Riyadh, Saudi Arabia. I worked as a part time consultant expert in the Saudi Arabian Standards Organization, Riyadh, Saudi Arabia. Moreover, he was appointed as the chairman of the mechanical engineering department for four years at college of engineering in Al Imam Mohammad Ibn Saud Islamic University. Currently he is the director of the college of engineering research center. During his academic career he developed and taught more than 15 undergraduate courses. Some of these courses are Statics, Dynamics, Basic electric circuits and electronics, Machine design, Vibration, Heat transfer, Thermodynamics, Fluid mechanics, introductory physics and many others. He also published many research papers in the area of computational heat transfer and thermodynamics. 